\title{
Comfort signatures: How long-term studies of occupant satisfaction in office buildings reveal on-going performance
}

\begin{abstract}
Occupant surveys reveal how people in buildings perceive their internal environments. The Soft Landings extended handover process, which requires project teams to focus more on operational outcomes, has led to the use of occupant surveys during a three year Soft Landings aftercare period to provide a means of checking whether the desired outcomes have been met. However, little is known of the longitudinal perceptions of occupant satisfaction in buildings and the relationships between those perceptions, and the many environmental, seasonal and functional comfort variables that act upon occupant satisfaction. This paper reports the results of time-series surveys on two office buildings. The analysis describes occupant perceptions have altered over time, and charts the main physical changes. Occupant satisfaction scores have been compared with the technical, organisational and functional contexts in the work environments, such as density, workgroup sizes, and cellular and open-plan layouts, to determine whether changes in these parameters have significantly altered levels of perceived occupant comfort and productivity. The research found stability in some contexts but statistically-significant declines in others. Conclusions are made regarding the key operational factors that may contribute to changes in occupant satisfaction over time. Factors that might constitute limits to office carrying capacity are discussed.
\end{abstract}

\section{Practical application}

The growing use of the Soft Landings approach to building procurement and handover, with greater emphasis on designing for improved operational outcomes, is creating a demand to understand more about occupant needs and expectations. The central government equivalent - Government Soft Landings - is similarly placing a requirement on public sector construction projects to deliver buildings with improved environmental and functional outcomes. Delivering these expectations requires construction professionals to develop skills in building performance evaluation, particularly in understanding the primary drivers that lead to high occupant perceptions of comfort, health, productivity and wellbeing. This research provides real-world guidance to clients and their design advisors on the key factors for ensuring long-term occupant satisfaction, while for building management professionals the research identifies some organisational risk factors that may lead to a fall in satisfaction during long-term operation.

Keywords Soft Landings, occupant surveys, wellbeing, facilities, comfort

\subsection{Introduction}

The use of occupant surveys to study human comfort perceptions in domestic and nondomestic buildings has increased with the increased availability of occupant satisfaction surveys. Such surveys are becoming popular for making associations between a building's physical and organisational characteristics and the reported experiences of the occupants. However, little is known about the accuracy of occupant comfort perceptions, their volatility over time, and therefore whether the perceptions can be trusted. It is also not known whether shifts in the physical and organisational characteristics of a building are fairly 
reflected in occupants' perceptions of comfort and the functionality of their work environment. As a consequence, designers and building operators tend to rely on instrumentation for insights into comfort conditions, rather than trust what may be regarded as more loosely calibrated and subjective perceptions of building users.

Most published comfort analyses have relied on large cohort studies of office buildings, such as the NIOSH and BASE databases on which sick building research was conducted in the 1990s $(1,2)$, and similar research conducted in Europe on indoor air quality (3). While these databases offer large distributions for linear regressions, for example between environmental variables such as winter and summer air quality with occupants' health perceptions (3), they usually lack contextual detail beyond simple classification of building typology or form of ventilation. Little is reported about the operational characteristics of the buildings: their condition, the way they are managed, and the approach to environmental control. Nothing is known about whether the buildings are operating at or below their design carrying capacities, or whether they were being exceeded at the time of the studies.

The exploratory research described in this paper is based on longitudinal case studies of office buildings for which changes in physical context have been mapped against changes in occupant comfort perceptions over periods of between three and 21 years. The studies re-applied the same occupant survey methodology almost identically in each case. Contextual details such as occupant numbers, spatial configuration, space use, and environmental control have been recorded. Occupants' numerical survey scores and their free-text feedback have been analysed with reference to the physical and organisational contexts prevailing at the time of each survey.

The aim of the research was to determine whether occupants' perceptions of comfort in each building were significantly different between surveys, and, if so, whether those changes in perception could be related to each building's physical and organisational characteristics. The field research also sought to identify whether satisfaction scoring in the surveys exhibited randomness or was a reasonable and possibly accurate reflection of conditions.

\subsection{Research methodology}

The research methodology used the Building Use Studies (BUS) occupant survey (4). The BUS survey is a systematically-applied paper questionnaire designed to obtain feedback from building occupants on their satisfaction with built environment conditions. The forerunner of the BUS was developed in the 1980s (5). The survey developed into the Office Environment Survey (OES) (6). In 1995, the OES was modified for use in the Postoccupancy Review of Buildings and their Engineering (PROBE) series of building investigations run by the Journal of the Chartered Institution of Building Services Engineers (7).

The first PROBE surveys used the original OES questionnaire, while the later PROBE surveys used a streamlined version of the OES developed by Adrian Leaman of Building Use Studies and Dr Gary Raw of the BRE (8). The later BUS questionnaire is almost identical to the version used in the current research. The BUS uses 7-point Likert numerical 
scoring scales. The direction of scales generally follows the rule of allocating low numerical codes to categories that indicate a low quantity of a variable (or value), and high codes to categories indicating a high quantity (9). For example, overall comfort is scaled as 1 : Unsatisfactory and 7: Satisfactory. However, some scale labels are bi-modal, e.g. for air conditions 1 is 'dry' and 7 is 'humid'. A satisfactory score would thus be '4'.

The BUS survey elicits occupants' perceptions of a wide range of environmental and functional factors such as comfort perceptions of temperature and air conditions in summer and winter, noise disturbance, and the provision of daylight and electric light. Other questions focus on functional factors, such as space use, storage, and meeting rooms.

It is not an objective of the research to validate occupants' perceptions against physical measurements, records of system setpoints, or any other environmental parameters recorded between surveys. The occupant perceptions measured by the BUS survey are held to be the best obtainable record of the wide variety of comfort and usability conditions prevailing over time. Where available, empirical comfort data may be helpful for explaining occupant perceptions, but it may be counter-productive to use such data in an attempt to validate or challenge those perceptions, as the research objective would become an exercise in accounting for differences. Disparity with the quantified truth may be taken as evidence of perversity in occupants' responses. However, for many reasons data from physical monitoring and records of environmental systems may not be definitive. Such data can be prone to measurement and calibration error. Data may be discontinuous (either in type, quality, or accuracy). Context-critical aspects, such as air movement or speech intelligibility, may not be measured. Measurements in one location may be unrepresentative of conditions experienced in another. Some researchers are attempting such comparisons, but causality is difficult to prove and relationships may be non-linear (10). For these reasons this research is relying almost wholly on longitudinal occupant perceptions in describing long-term performance of the case study offices, with the physical characteristics of the occupied spaces - and the uses to which they are put - as the independent variables.

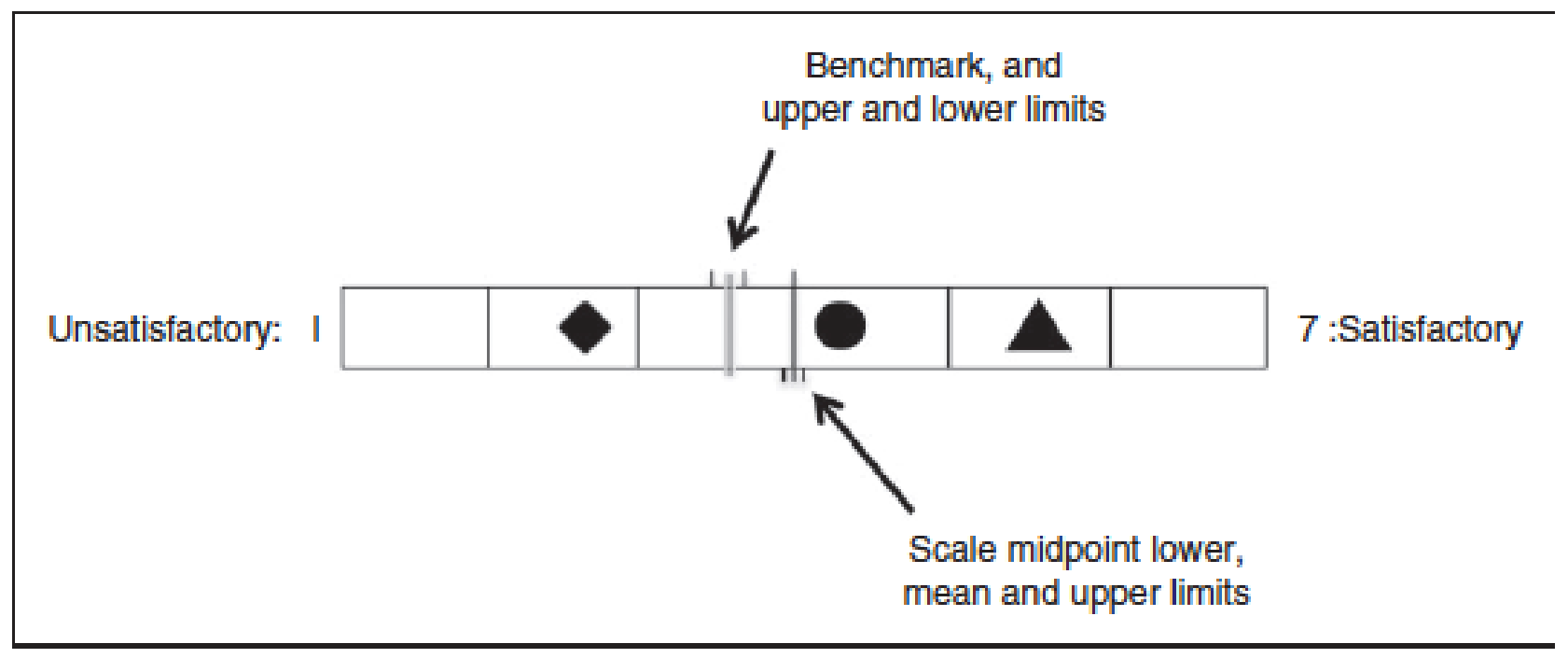

Figure 1: Explanatory graphic for the BUS summary charts 
BUS survey graphics are explained in Figure 1. The BUS comprises a numerical 1-7 interval scale that enables occupants to grade their responses from unsatisfactory to satisfactory. Respondents can select the midpoint for a comfort variable regarded as acceptable (i.e. neither good nor bad).

BUS statistics are based on mean scores with 95\% confidence limits for both the building study dataset and benchmark dataset. The confidence interval is a range of values around that statistic that are believed to contain, with a chosen probability (e.g. 95\%), the true value of that statistic. The marker shapes in the BUS summary charts (Figures 2-6) are related to a score's position relative to the upper and lower confidence limits of the study dataset, and likewise for the relevant BUS benchmark dataset. A change in comfort variable status from triangle to circle, or from a circle to a diamond red, and vice versa, reflects a mean score relative to the confidence limits. Note that the BUS summary charts only show BUS benchmarks and scale midpoints. The shape of the chart icons reflects values that lie outside both sets of confidence limits.

The mid-1990s BUS surveys did not cover perceptions of design, needs and health. It is therefore not possible to analyse all factors longitudinally. However, the core comfort variables such as temperature, air conditions, noise and lighting were consistent in all versions of the OES and BUS questionnaires.

\subsection{Research method}

The researcher chose six buildings for detailed study. The selection process involved ranking buildings on the availability of BUS data, access to records of each building's design and operational history, and permission carry out a new BUS survey. It was also important that the historical BUS survey data contained viable response samples and that the surveys themselves were conducted well. In most cases the researcher was familiar with how the surveys had been carried out or had been involved, directly or indirectly, with the surveys. All BUS surveys were conducted manually, i.e. the researcher visited the buildings in person to hand out and retrieve questionnaires.

An additional question on the usability of controls was added to the most recent BUS surveys. This was motivated by research that suggests that providing people with the means to control their indoor environment can improve occupant satisfaction (11). Similarly, a question on perceptions of occupant density was added. This was motivated by previous research that suggested that existing models of occupant satisfaction should include occupancy patterns and social constraints (12).

The case study research required a method of linking dependent and independent variables. The researcher devised a systematic method of defining and classifying the physical and behavioural characteristics of the occupied spaces. Physical and organisational contexts in each building were categorised for each survey period as a set of nested contexts, as follows: 
- Primary context: Whole building physical features and dimensions, physical characteristics of occupied and non-occupied spaces including shared spaces such as circulation and toilet facilities, management characteristics.

- Second level context: characteristics of discrete zones such as by floor, by cellular and open-plan spaces (and the percentage of each), approach to environmental control, floor areas, occupation densities (measured and occupant-perceptions), and the nature of the occupancy, i.e. single occupier, multi-occupied or tenanted.

- Third level context: sub-categorisation of zone type, i.e. separation by window and non-window seats, and by work-group sizes. Occupant perceptions of conditions in those sub-zones are included.

- Fourth level context: overall conditions as perceived by occupants in terms of overall comfort, and perceived health and productivity. These are effectively the outcome metrics. The outcome metrics were analysed separately for the subcontexts of window position and office type.

Note the physical parameters in the two case-study buildings remained fixed over time (depth of plan, floor to ceiling heights), while other parameters such as office partitioning changed.

The mean values of individual BUS response distributions were compared with the response distributions from earlier surveys. Statistical differences between the population responses were calculated at a 95\% confidence level $(P<0.05)$ using the Mann Whitney two-tailed $U$-test (a non-parametric test for unpaired samples) (13). Mann-Whitney is a slightly tougher check for significance than a standard student $t$-test as it ranks scores. Note that while $\mathrm{P}<0.05$ is a standard threshold for determining statistical significance, the researcher regards it as an overly stringent test for social science data. Nevertheless, it was decided to maintain the $\mathrm{P}<0.05$ threshold as all differences at a $95 \%$ confidence level should be traceable to a likely root cause. The direction of movement of a comfort variable in the longitudinal studies is believed to be as important, if not more insightful, than adherence to a arbitrary statistical threshold. For example, a statistical difference greater than $\mathrm{P}<0.05$ (for example, $<0.2$ or $80 \%$ confidence in an association) may enable credence to be given to subtle movements in occupant perception scores, where something in a building has changed enough for occupants to report a discernable effect on their personal comfort or work performance. Readers are therefore advised to consider the direction in which mean scores have moved and the distribution of respondents' scores in the descriptive statistics.

Note that statistical analysis by gender and by age profile is not reported in this paper for space reasons. Moreover, in some cases sub-samples were too small for statistical analysis. 


\subsection{The case study buildings}

The results of office buildings are reported in this paper. Building $A$ is a four-storey $3250 \mathrm{~m}^{2}$ narrow-plan university building. Building $B$ is a $7300 \mathrm{~m}^{2}$ two-storey mixed-mode deep-plan office building. Both buildings have elements of mixed mode operation: Building $A$ is predominantly mechanically-ventilated but with openable vents and windows, while Building $B$ is predominantly naturally-ventilated with back-up mechanical ventilation. Building $A$ is narrow-plan and Building $B$ is deep-plan.

Building A was constructed in the mid-1990s. Upon opening, the top two floors contained 50 cellular offices for about 70 staff. The building has undergone physical internal changes since 1998. Some areas have since changed use while others have been enlarged. In 2010 the partitions of ground floor seminar rooms were removed to create an open-plan office for 32 staff. Shortly thereafter a kitchen and dining rooms on the second floor were refurbished to create an open-plan office for 22 administrators. Common rooms on the first and second floors also became shared offices. By the time of the third BUS survey the cellular office accommodation had become a mix of shared and open-plan offices. Occupant satisfaction was measured using the BUS survey in 1998 and again in 2011. A third BUS survey was carried out in May 2015.

Building B was constructed in 2006. The multi-pitched roof is punctuated with north-facing skylights, either side of which are wind-assisted extract ventilators. Internal courtyards break up the deep-plan offices, while lightwells in the first floor mezzanine allow daylight to reach the ground floor. The client's objective to reduce energy consumption led to a relaxation in winter and summer set-points. Occupants were told not to expect stable conditions and to vary their clothing layers depending on weather conditions. Initially, the roof and window ventilation could be operated by occupants seated around the building's perimeter through the use of switches. Due to difficulties with reaching consensus in the open-plan areas when windows should be open or closed, control was centralised by the building operator in 2011.

The building was designed for 420 workstations and additional hot desks. This rose to 475 at the time of occupancy. By 2013, occupancy had risen to 630 people with 495 workstations. Some areas have smaller desks to accommodate the higher numbers. By 2015, the fixed desk allocation had risen to 586, with some departments having higher densities than others. Security swipe-card records show that occupancy can be 650 midweek. The first BUS occupant survey was performed in November 2006. A repeat survey was carried out in June 2015.

\subsection{Results}

Table 1 shows the survey dates, occupancy numbers and survey response rates. While survey response rates vary, all are well above the sample sizes required for statistical testing. The response rate for Building A was not recorded in 2011, but based on desk 
numbers it is thought to be at least $50 \%$ of the total occupancy, not all of whom would have been in attendance on the day of the survey.

Table 1: Details of the BUS surveys carried out on the pilot studies. Data prior to 2011 are best obtainable estimates.

\begin{tabular}{|l|c|c|c|c|c|}
\hline & $\begin{array}{c}\text { Survey dates } \\
\text { (month/year) }\end{array}$ & $\begin{array}{c}\text { Maximum occupancy } \\
\text { approx. (in year } \\
\text { order) }\end{array}$ & $\begin{array}{c}\text { Occupancy day of } \\
\text { survey (in year } \\
\text { order) }\end{array}$ & $\begin{array}{c}\text { BUS } \\
\text { respondents } \\
\text { (in year order) }\end{array}$ & $\begin{array}{c}\text { Response rate } \\
\text { (in year order) }\end{array}$ \\
\hline Building A & $\begin{array}{c}\text { Jan 98/ Nov 11/ } \\
\text { June 15 }\end{array}$ & $70 / 120 / 120$ & $70 / \mathrm{N} / \mathrm{A} / 100$ & $42 / 60 / 90$ & $58 \% / \mathrm{N} / \mathrm{A} / 90 \%$ \\
\hline Building B & Nov 06/May 15 & $475 / 586$ & $255 / 500$ & $242 / 361$ & $92 \% / 72 \%$ \\
\hline
\end{tabular}

The 1998, 2011 and 2015 BUS summary results for Building A are shown in Figures 2-4. The summary charts are illustrative versions of the standard BUS graphics for the 12 key comfort variables. The relationship of mean scores to BUS benchmark and scale midpoint confidence limits are indicated by the icon shape described in Figure 1. The important relationship for the current research is the relationship (and movement over time) of a variable to a scale midpoint. (BUS benchmarks are not used in the research.)

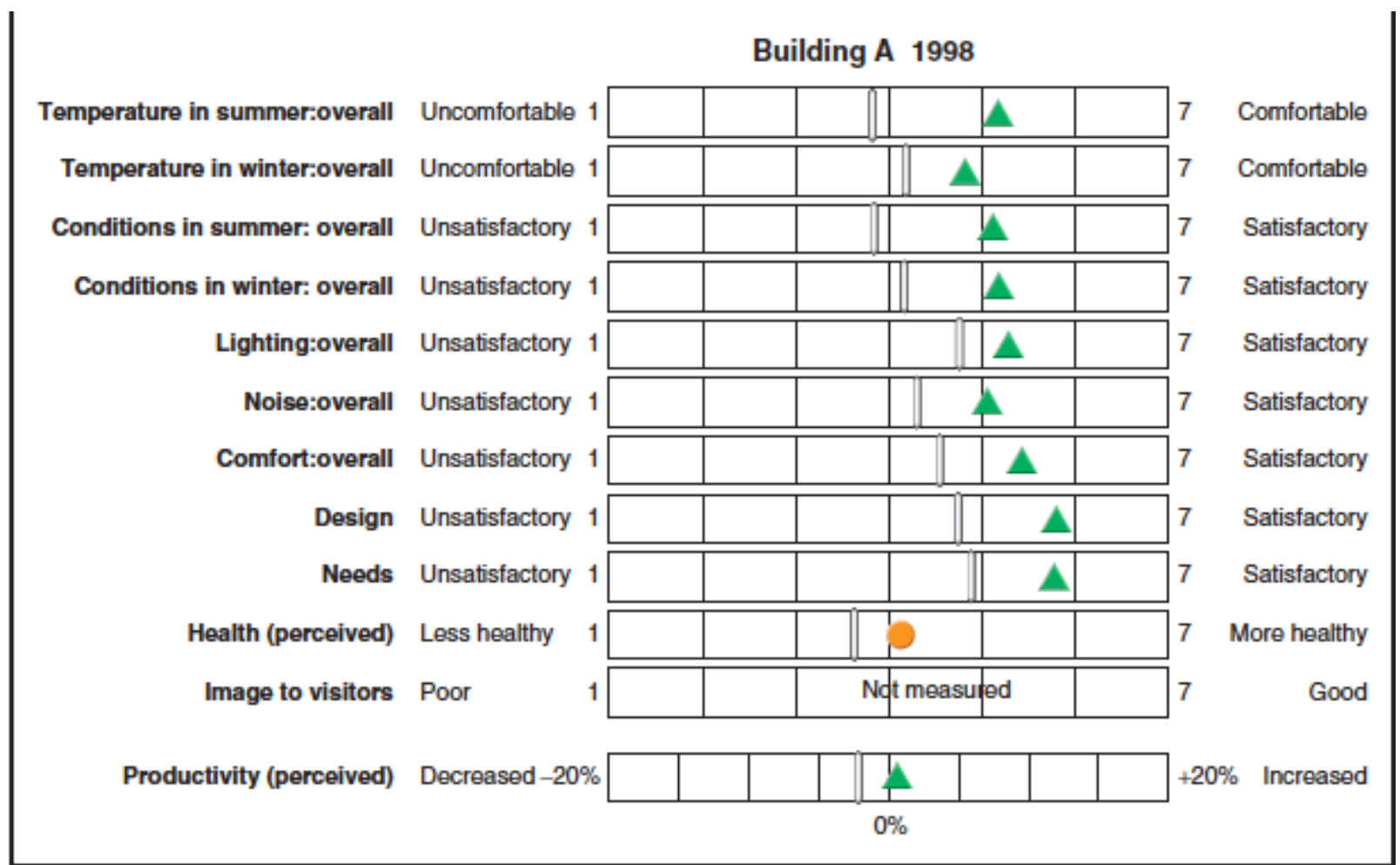

Figure 2: Building A study results for 1998 based on mean scores on the BUS 1-7 point scale. Note that occupants' self-assessed productivity is on a $-20 \%-+20 \%$ scale. 
Bullding A 2011

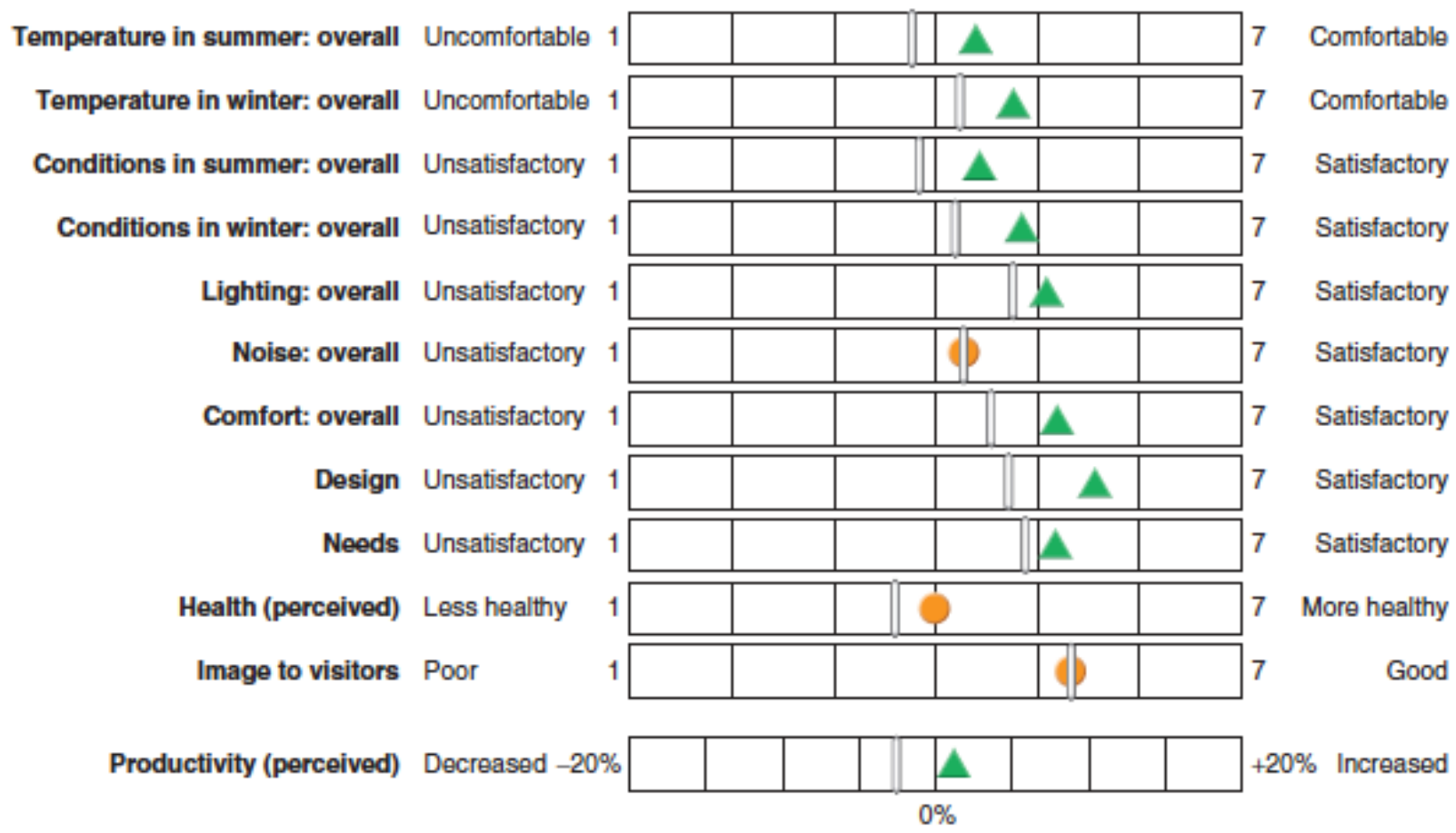

Figure 3: Building A study results for 2011. Performances on all summary variables, with the exception of temperature in winter, have declined compared with 1998.

Bullding A 2015
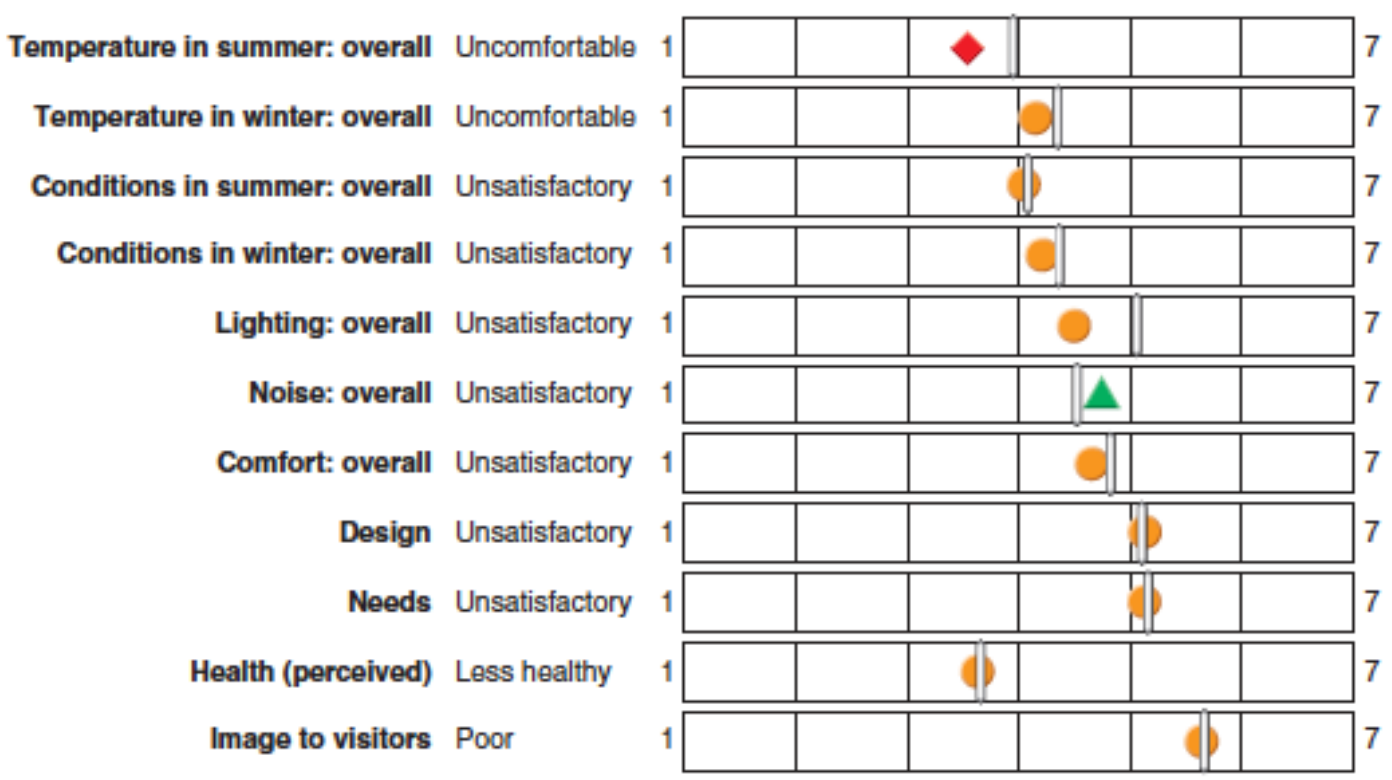

Comfortable

Comfortable

Satisfactory

Satisfactory

Satisfactory

Satisfactory

Satisfactory

Satisfactory

Satisfactory

More healthy

Good

Productivity (perceived) Decreased $-40 \%$

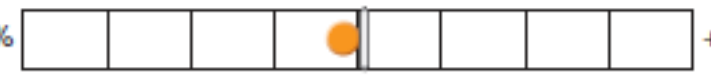

$+40 \%$ Increased

$0 \%$

Figure 4: Building A study results for 2015. Temperature in summer and perceptions of health and productivity are now below their scale midpoints. 
Figures 2-4 show how the main comfort perceptions of occupants in Building A have changed since 1998. While the comfort scores are still acceptable relative to the neutral scale midpoint (neither good nor bad), most scores have declined. The decay between surveys is notable for the symmetry of the data. Occupant scoring exhibits neither randomness nor volatility. The symmetry of decline suggests a rationale behind the occupant scoring.

Figures 5 and 6 show the performance in summary variables for Building B. Some variables in Building $B$ have declined in the eight years between surveys, again with a consistency and symmetry of pattern that does not suggest arbitrary scoring. Some variables, such as lighting, have stayed the same or slightly improved.

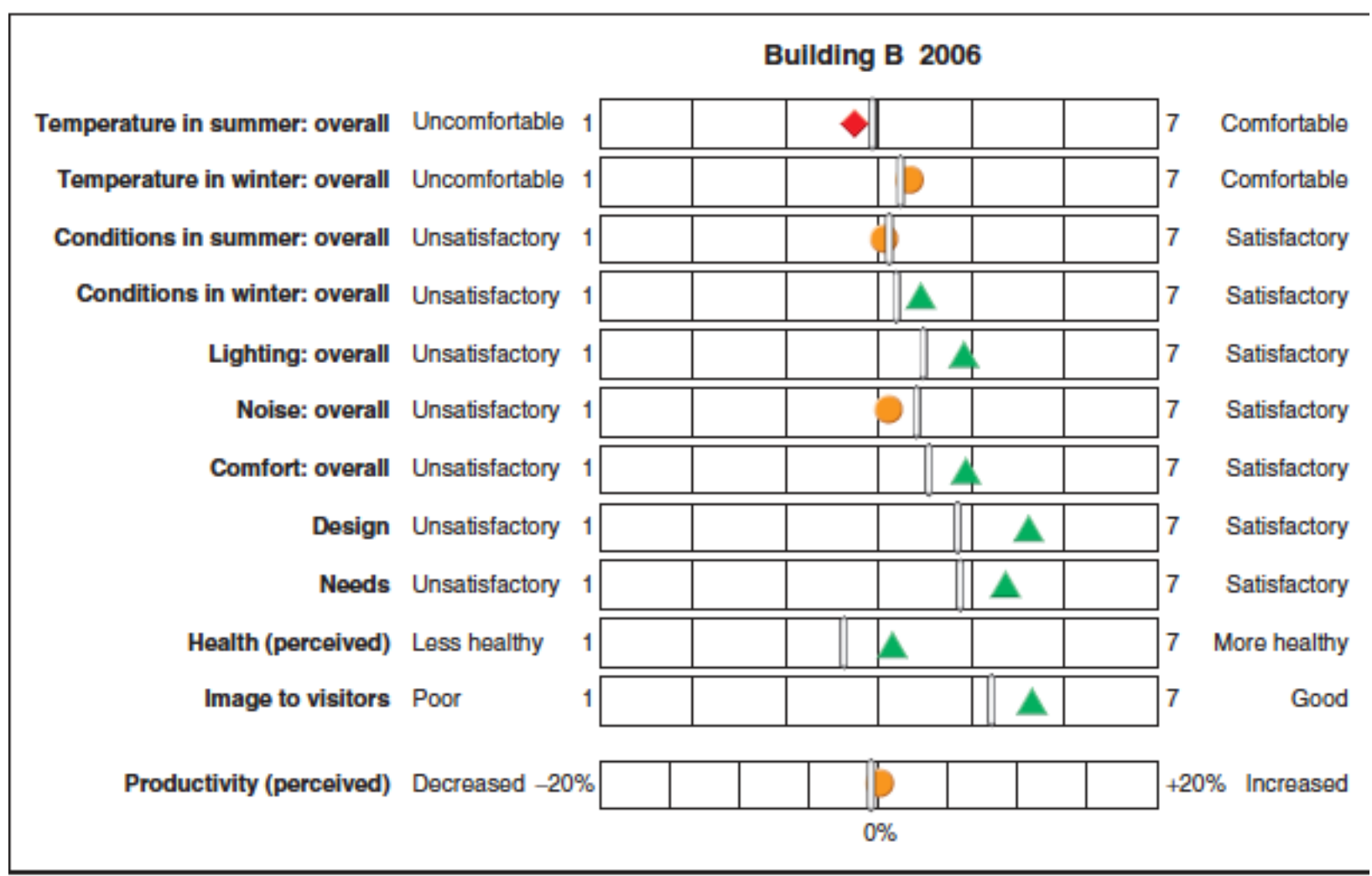

Figure 5: Building B study results for 2006. Temperature in summer is the only variable below the scale midpoint. Self-assessed productivity is ranked on a $-\mathbf{2 0 \%}$ $+20 \%$ scale. 
Bullding B 2015

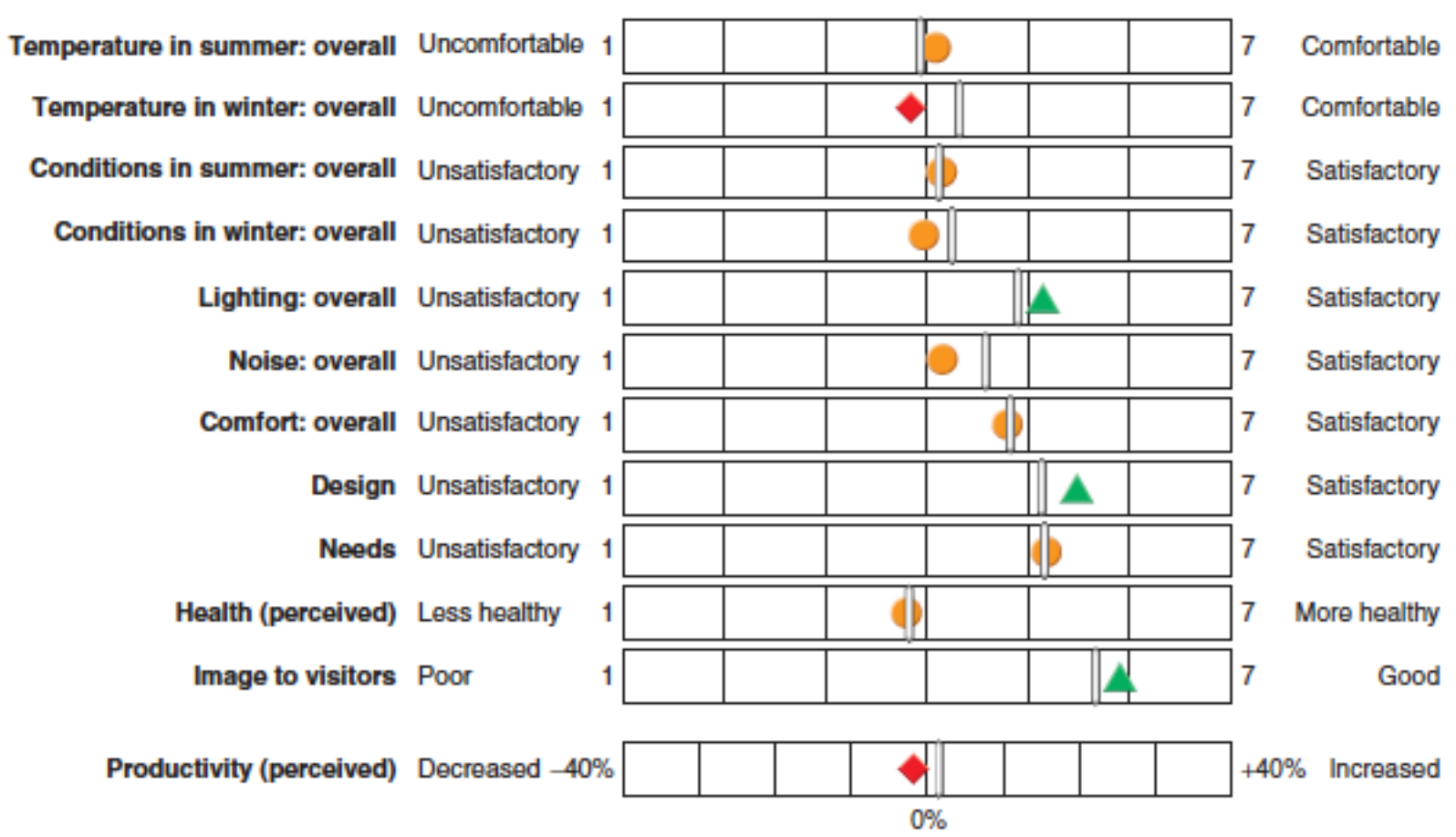

Figure 6: Building B study results for 2015. Temperature in summer has improved, but temperature in winter is below midpoint, along with perceived heath and productivity (ranked in 2011 on a $-40 \%-+40 \%$ scale).

\subsection{Detailed results: Building $A$}

An aim of the research is to link occupant satisfaction scores, and the change in those scores over time, to physical characteristics prevailing at the time of the surveys. Where possible this linkage included changes in operating characteristics, such as facilities management activities, seating densities, and storage provision, although it is acknowledged that these factors will be in a state of flux between surveys. The purpose of the context structure was to put some shape and order to the physical factors, and to identify the combinations of factors that might be cause a change in occupants' perceptions.

Table 2: Building A primary level context, physical and occupancy characteristics.

\begin{tabular}{|c|c|c|c|c|c|}
\hline \multirow[t]{2}{*}{ Characteristic } & \multirow[t]{2}{*}{ Source } & \multicolumn{3}{|c|}{ Context } & \multirow{2}{*}{$\begin{array}{l}\text { Major } \\
\text { change }\end{array}$} \\
\hline & & 1998 & 2011 & 2015 & \\
\hline Orientation & Record drawings & \multicolumn{3}{|c|}{ East-west } & \\
\hline Treated floor area (TFA) & Drawing take-off & \multicolumn{3}{|c|}{$3130 \mathrm{~m}^{2}$} & \\
\hline Storey height & Record drawings & \multicolumn{3}{|c|}{4 (including basement) } & \\
\hline Floor ceiling height & Measurement & \multicolumn{3}{|c|}{$2800 \mathrm{~mm}$} & \\
\hline Ventilation type & Record drawings & \multicolumn{3}{|c|}{$\begin{array}{l}\text { Mixed mode (mechanical with openable } \\
\text { windows) }\end{array}$} & \\
\hline Ratio window to wall & Record drawings & \multicolumn{3}{|c|}{$25 \%$ window (average) } & \\
\hline
\end{tabular}




\begin{tabular}{|c|c|c|c|c|c|}
\hline $\begin{array}{l}\text { Envelope/volume ratio (3107 } \\
\mathrm{m}^{2} / 13,280 \mathrm{~m}^{3} \text { ) }\end{array}$ & Measurement & & 4.2 & & \\
\hline Control strategy & Observation & Mixed & Mixed & Mixed & \\
\hline $\begin{array}{l}\text { Spatial type (discounting Level - } \\
1 \text { rooms) }\end{array}$ & Record drawings & Cellular & Cellular/shared & Mixed & $\mathbf{Y}$ \\
\hline $\begin{array}{l}\text { Percentage split cellular/shared } \\
\text { to open-plan }\end{array}$ & Drawing take-off & $100 \%$ & $13.5 \% / 86.5 \%$ & $27.7 \% / 72.3 \%$ & $\mathbf{Y}$ \\
\hline Plan depth (offices maximum) & Drawing take-off & & lorth $2.6 \mathrm{~m}$, South & $6.8 \mathrm{~m}$ & \\
\hline $\begin{array}{l}\text { Maximum workstation depth (by } \\
\text { desk) }\end{array}$ & & & 3 & & \\
\hline $\begin{array}{l}\text { Maximum distance to beverage } \\
\text { point }\end{array}$ & Drawing take-off & $35 \mathrm{~m}$ & $50 \mathrm{~m}$ & $50 \mathrm{~m}$ & \\
\hline Maximum distance to toilet & Drawing take-off & Lev & 0: $41 \mathrm{~m}$, Levels & $\& 2: 57 \mathrm{~m}$ & \\
\hline $\begin{array}{l}\text { Maximum distance to vertical } \\
\text { circulation }\end{array}$ & Drawing take-off & & $35 \mathrm{~m}$ & & \\
\hline $\begin{array}{l}\text { Maximum distance to main } \\
\text { entrance }\end{array}$ & Drawing take-off & $50 \mathrm{~m}$ & & & \\
\hline $\begin{array}{l}\text { Percentage gender split } \\
\text { (female/male) }\end{array}$ & BUS Response & $76 / 24$ & $75 / 25$ & $72 / 28$ & \\
\hline Age profile $(n<30 / n>30)$ & BUS Response & $7 / 35$ & $10 / 49$ & $8 / 87$ & \\
\hline Occupant seats & & $70^{1}$ & $120^{2}$ & $160^{3}$ & $\mathbf{Y}$ \\
\hline Workplace density (overall area) & Drawing take-off & $1 / 45 \mathrm{~m}^{2}$ & $1 / 26 m^{2}$ & $1 / 19 \mathrm{~m}^{2}$ & $\mathbf{Y}$ \\
\hline
\end{tabular}

${ }^{1}$ Including 21 for second floor open-plan office

${ }^{2}$ Actuals unknown. Derived using BUS respondents segregated by gender as a proxy for the total occupancy.

${ }^{3}$ Including 45 in the ground floor open-plan office and four extra desks in the second floor open-plan office.

Table 2 shows that the significant changes in Building A are the shift from $100 \%$ cellular to $27.7 \%$ shared and open-plan. Occupancy has increased from around 68 staff to 128.

Cellular accommodation for single or dual occupancy now accounts for $840.7 \mathrm{~m}^{2}$, while shared offices of fewer than five staff occupy $171 \mathrm{~m}^{2}$. Fully open-plan office space accounts for $323 \mathrm{~m}^{2}$. Although overall density in 2015 is still above British Council for Offices (BCO) recommendations (14) of one person/8-13 $\mathrm{m}^{2}(15)$, the density in the $165.6 \mathrm{~m}^{2}$ ground floor open-plan office is 1 person/5.3 $\mathrm{m}^{2}$ (Figure 7), while in the second floor open-plan office it is one person $/ 7.5 \mathrm{~m}^{2}$ (Figure 8). Note that density data is not available for 1998.

Given the shift from cellular to open-plan, it is not surprising that more staff perceive themselves to be working in shared office space of eight or more people. In 2011, a third of staff perceived themselves to be sharing with eight or more (Figure 9). By 2015, half the staff reported being in the largest workgroup (Figure 10). Occupant perceptions reported through the BUS survey therefore corroborate the area and occupant density measurements. 


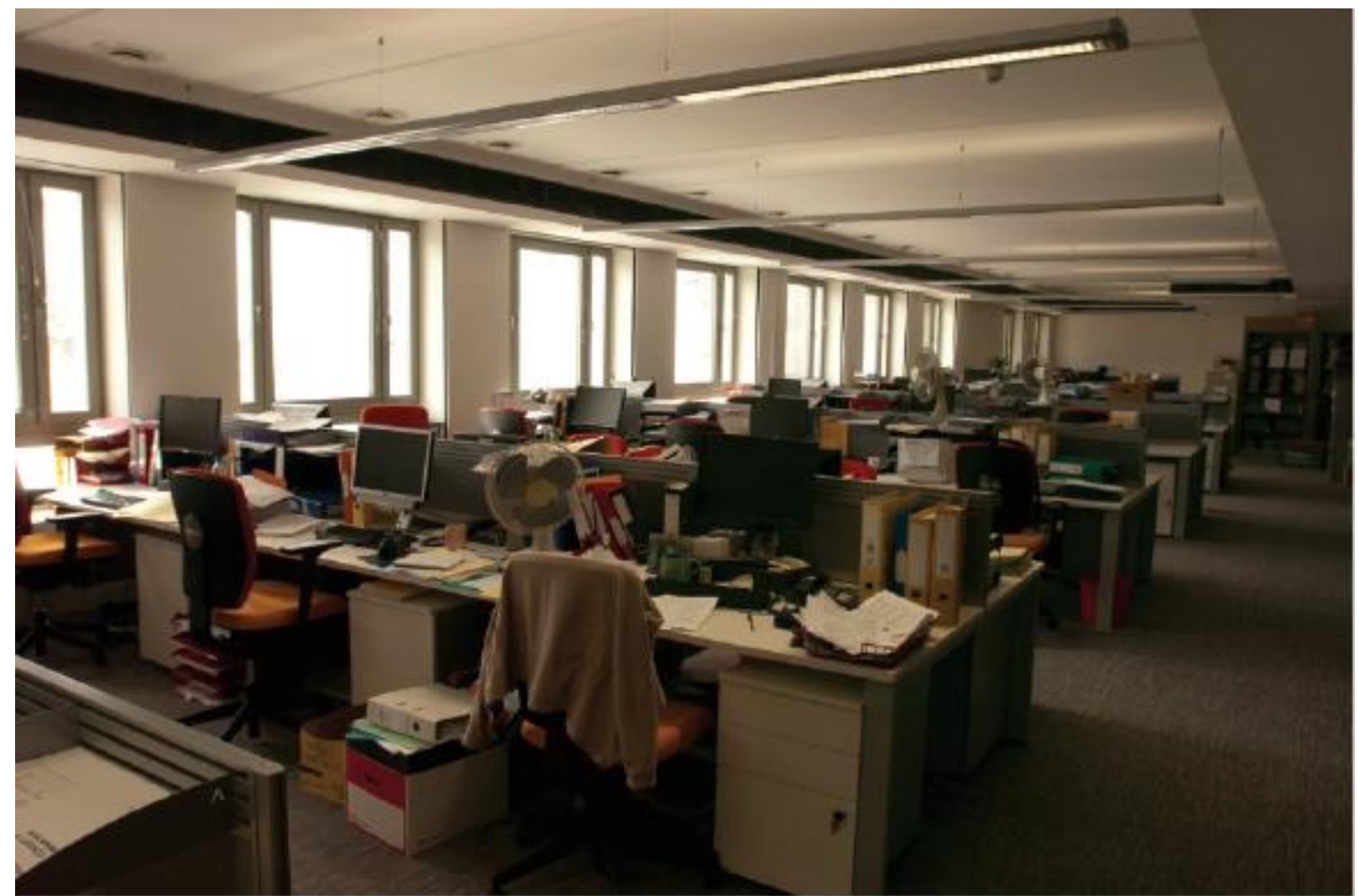

Figure 7: Building A ground floor. The hatched area shows the open-plan office created in a former teaching area.

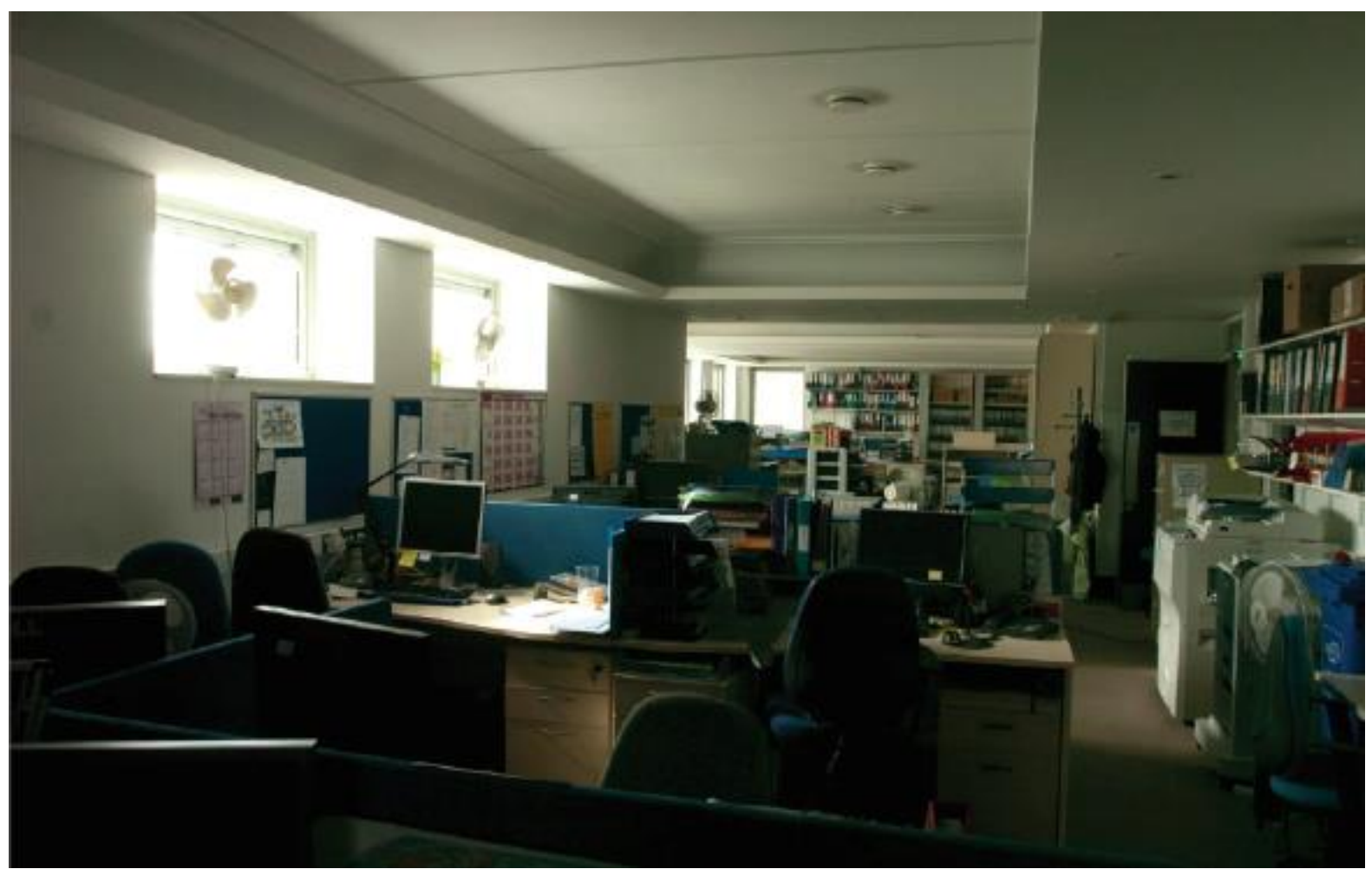

Figure 8: Building A second floor. The hatched area shows the open-plan office created in a former dining area. 


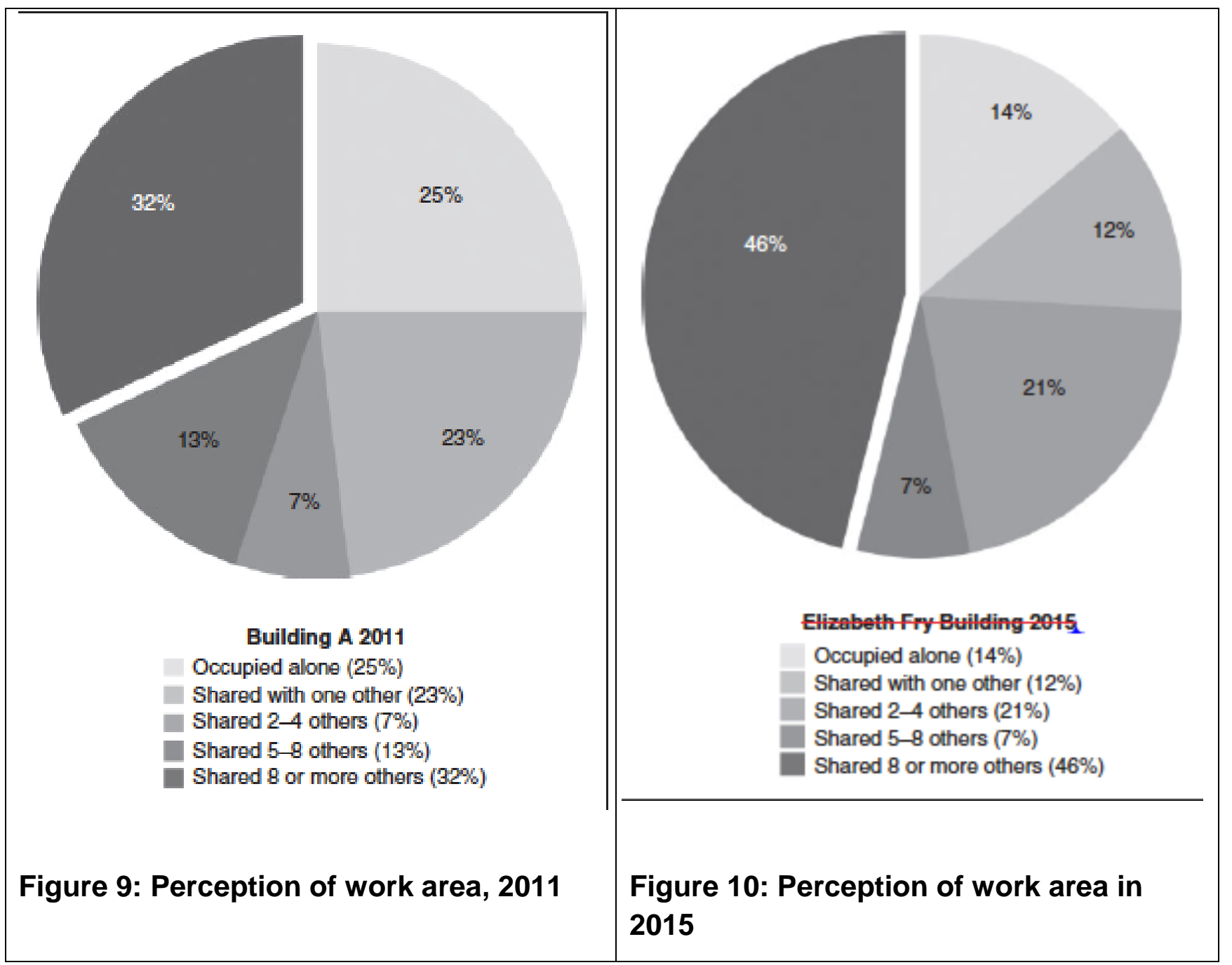

In 2011, occupants in Building A reported a universal decline in the building's thermal and air quality conditions, although not to levels that were statistically different (Table 3). However, compared with conditions in 1998, perception of summertime temperature in 2011 was over an integer lower than 1998, and lower still by nearly half an integer in 2015. Perceptions of temperature in winter and air conditions in winter also fell in 2015 compared with 2011.

Table 3: Building A overall main seasonal scores. All mean values over the 17-year period are universally in decline.

\begin{tabular}{|l|c|c|c|c|c|c|c|c|c|c|}
\hline \multirow{2}{*}{ Comfort variable } & \multicolumn{3}{|c|}{$\begin{array}{c}\text { Population } \\
\text { samples }\end{array}$} & \multicolumn{3}{|c|}{$\begin{array}{c}\text { Survey mean } \\
\text { scores }\end{array}$} & \multicolumn{2}{c|}{ Two tailed U-Test ${ }^{1}$} & $\begin{array}{c}\mathbf{2 0 1 1}^{\text {* }} \mathbf{P} \square \mathbf{0 . 0} \\
\mathbf{5}\end{array}$ & $\begin{array}{c}\mathbf{2 0 1 5}^{*} \\
\mathbf{P} \square<0.05\end{array}$ \\
\cline { 2 - 12 } & $\mathbf{1 9 9 8}$ & $\mathbf{2 0 1 1}$ & $\mathbf{2 0 1 5}$ & $\mathbf{1 9 9 8}$ & $\mathbf{2 0 1 1}$ & $\mathbf{2 0 1 5}$ & $\mathbf{1 9 9 8 / 2 0 1 1}$ & $\mathbf{2 0 1 1 / 2 0 1 5}$ & & \\
\hline Temperature in summer & 33 & 57 & 72 & 5.30 & 3.93 & 3.47 & 0.0017 & 0.1795 & $\mathrm{Y}$ & \\
\hline Temperature in winter & 41 & 57 & 72 & 4.66 & 4.86 & 4.08 & 0.6526 & 0.0281 & & $\mathrm{Y}$ \\
\hline Conditions in summer & 32 & 55 & 72 & 4.88 & 4.18 & 4.03 & 0.1044 & 0.6721 & & \\
\hline
\end{tabular}




\begin{tabular}{|l|l|l|l|l|l|l|l|l|l|l|}
\hline Conditions in winter & 41 & 59 & 71 & 5.20 & 4.83 & 4.10 & 0.2548 & 0.0211 & Y \\
\hline Natural light & 39 & 60 & 75 & 4.46 & 3.42 & 3.09 & 0.0046 & 0.1726 & Y & \\
\hline Glare from natural light & 38 & 60 & 75 & 3.55 & 3.12 & 3.12 & 0.2646 & 0.9735 & & \\
\hline
\end{tabular}

${ }^{1}$ Mann-Whitney non-parametric un-paired samples U-Test for 2011 versus 1998, and 2015 versus 2011.

Analysis of the outcome comfort variables for all three surveys (Table 4) shows consistent fall in occupant perceptions of overall comfort, and perceived health and productivity. Although the distribution of the samples are not statistically different at $\mathrm{P}<0.05$, the decline in satisfaction for overall comfort and perceived health in 2015 is approaching statistical significance compared with 2011. It depends where the statistical threshold is placed, as explained in Section 2.

Table 4: Building A overall: Nest 4 outcome variables (Occupant perceptions)

\begin{tabular}{|l|c|c|c|c|c|c|c|c|c|}
\hline \multirow{2}{*}{ Outcome variables } & \multicolumn{3}{|c|}{$\begin{array}{c}\text { Population } \\
\text { samples }\end{array}$} & \multicolumn{3}{c|}{ Mean scores } & Two tailed U -Test ${ }^{1}$ & $\begin{array}{c}\text { Samples different } \\
\text { at } P<0.05\end{array}$ \\
\cline { 2 - 10 } & $\mathbf{1 9 9 8}$ & $\mathbf{2 0 1 1}$ & $\mathbf{2 0 1 5}$ & $\mathbf{1 9 9 8}$ & $\mathbf{2 0 1 1}$ & $\mathbf{2 0 1 5}$ & $\begin{array}{c}\mathbf{1 9 9 8 /} \\
\mathbf{2 0 1 1}\end{array}$ & $\begin{array}{c}\mathbf{2 0 1 1} / \\
\mathbf{2 0 1 5}\end{array}$ & $\begin{array}{c}\mathbf{2 0 1 1 / 2 0 1 5} \text { statistical } \\
\text { difference only }\end{array}$ \\
\hline Overall comfort & 37 & 57 & 93 & 5.41 & 5.09 & 4.66 & 0.2569 & 0.0746 & $\mathrm{~N}$ \\
\hline Health (perceived) & 41 & 58 & 94 & 4.15 & 3.97 & 3.69 & 0.5249 & 0.0858 & $\mathrm{~N}$ \\
\hline Productivity (perceived) & 39 & 58 & 90 & $\mathrm{~N} / \mathrm{A}$ & 5.14 & 4.87 & $\mathrm{~N} / \mathrm{A}$ & 0.3529 & $\mathrm{~N}$ \\
\hline
\end{tabular}

${ }^{1}$ Mann-Whitney non-parametric un-paired samples U-Test for 2011 versus 1998, and 2015 versus 2011.

The outcome variable scores in Table 4 prompted investigation of the data to determine whether the fall in occupant satisfaction is due to variation in specific areas, i.e office type and seating location. The first step was to identify differences in occupant satisfaction in the shared and open-plan accommodation compared with the cellular and non-office areas. The scores from the ground floor open-plan office were combined with the responses from the second floor open-plan office to create a concatenated sample of 44 responses.

Table 5 shows that in 2015, occupants in open-plan areas reported statistically lower control over ventilation, lighting and noise, and marginally lower perception of the usability of controls.

Table 5: Building A control over environment factors.

\begin{tabular}{|r|c|c|c|c|}
\hline & \multicolumn{4}{|c|}{ Control over environment (Mann Whitney U-Tests) } \\
\hline Control variables & $\begin{array}{c}\text { Non-office \& } \\
\text { cellular }\end{array}$ & Open-plan & Two-tailed U-test & $\begin{array}{c}\text { Statistically different } \\
\text { at } \mathbf{P}<\mathbf{0 . 0 5}\end{array}$ \\
\hline Heating1 & $1.51(n=41)$ & $1.25(n=44)$ & 0.3697 & $\mathrm{~N}$ \\
\hline Cooling1 $^{1}$ & $2.31(n=42)$ & $2.16(n=43)$ & 0.8261 & $\mathrm{~N}$ \\
\hline Ventilation $^{1}$ & $4.02(n=42)$ & $2.72(n=43)$ & 0.0012 & $\mathrm{Y}$ \\
\hline Lighting $^{1}$ & $4.21(n=42)$ & $1.48(n=44)$ & 0.0001 & $\mathrm{Y}$ \\
\hline Noise & $2.45(n=42)$ & $1.59(n=44)$ & 0.0009 & $\mathrm{Y}$ \\
\hline
\end{tabular}




\begin{tabular}{|r|c|c|c|c|}
\hline Controls usability $^{2}$ & $4.04(n=27)$ & $3.21(n=34)$ & 0.0483 & $Y$ \\
\hline
\end{tabular}

${ }^{1}$ Means of respondent perceptions on 1-7 scale (Scale: 1 no control; 7 full control).

22015 survey only, mean score. (Scale: 1 = very poor, 4 = scale midpoint, 7 = very good).

Table 6 shows mean scores for the seasonal comfort variables from the BUS survey. While perceptions of thermal conditions in summer and winter are not statistically different (at $p$ $<0.05$ ) between open-plan offices and cellular and non-office areas, perceptions of overall air conditions in summer and winter do show statistical difference. Occupant satisfaction with the amount of natural light is also statistically lower in open-plan offices. Note that all 2015 values for open-plan offices are well below the BUS scale midpoint of '4'. (The daylight glare scores are acceptable, as a score of '1' equates to 'none'.)

Table 6: Seasonal variable scores for the open-plan office spaces compared with cellular and non-office spaces.

\begin{tabular}{|c|c|c|c|c|}
\hline & \multicolumn{2}{|c|}{ Occupant mean scores } & \multirow[b]{2}{*}{ Two-tailed U-test } & \multirow[b]{2}{*}{$\begin{array}{c}\text { Statistically different at } \\
\qquad P<0.05\end{array}$} \\
\hline & $\begin{array}{c}\text { Non-office and } \\
\text { cellular }\end{array}$ & $\begin{array}{c}\text { Shared and open- } \\
\text { plan }\end{array}$ & & \\
\hline Temperature summer $^{1}$ & $3.74(n=42)$ & $3.38(n=45)$ & 0.5131 & \\
\hline Temperature winter $^{1}$ & $4.42(n=45)$ & $3.80(n=44)$ & 0.1190 & \\
\hline Conditions in summer ${ }^{1}$ & $4.59(n=41)$ & $3.61(n=46)$ & 0.0062 & $\mathbf{Y}$ \\
\hline Conditions in winter ${ }^{1}$ & $4.55(n=44)$ & $3.80(n=44)$ & 0.0279 & $\mathbf{Y}$ \\
\hline Natural light $^{2}$ & $3.74(n=46)$ & $2.77(n=47)$ & 0.0046 & $\mathbf{Y}$ \\
\hline Natural lighting glare ${ }^{2}$ & $3.41(n=46)$ & $3.02(n=47)$ & 0.2232 & \\
\hline
\end{tabular}

${ }_{1}^{1}$ Means of respondent perceptions on 1-7 scale (Scale: 1 no control; 7 full control).

${ }^{2}$ Scale: 1 = Too little, 4 = scale midpoint, 7 = Too much).

In 1998, the building was operating in its design condition of mostly cellular accommodation for one or two people. The increase in the number of occupants in working in open-plan offices since 2011 has led to a lower percentage of staff reporting proximity to a window. The second-floor open-plan office was only included in the 2015 BUS survey, which accounts for much of the recent rise in non-window seats.

Respondents' mean scores were analysed for statistical differences between the comfort perceptions of those sitting next to openable windows and those who are no longer near a window. While the increase in overall staff numbers over the survey period allowed withinyear analysis for both the 2011 and 2015 surveys, allowance needed to be made for the small samples in the 2011 data for open-plan window seats. (The small number of people reporting a non-window seat in the 1998 survey precluded statistical analysis, as did separating samples by age profile.)

The statistical differences were not conclusive (Table 7). However, as explained above, it is believed that the chosen threshold for statistical significance masks meaningful shifts in occupant perceptions. The sample distributions for perceptions of summer conditions in window and non-window seats in 2011 and 2015 were plotted to identify any changes in the occupant responses (Figure 11). 


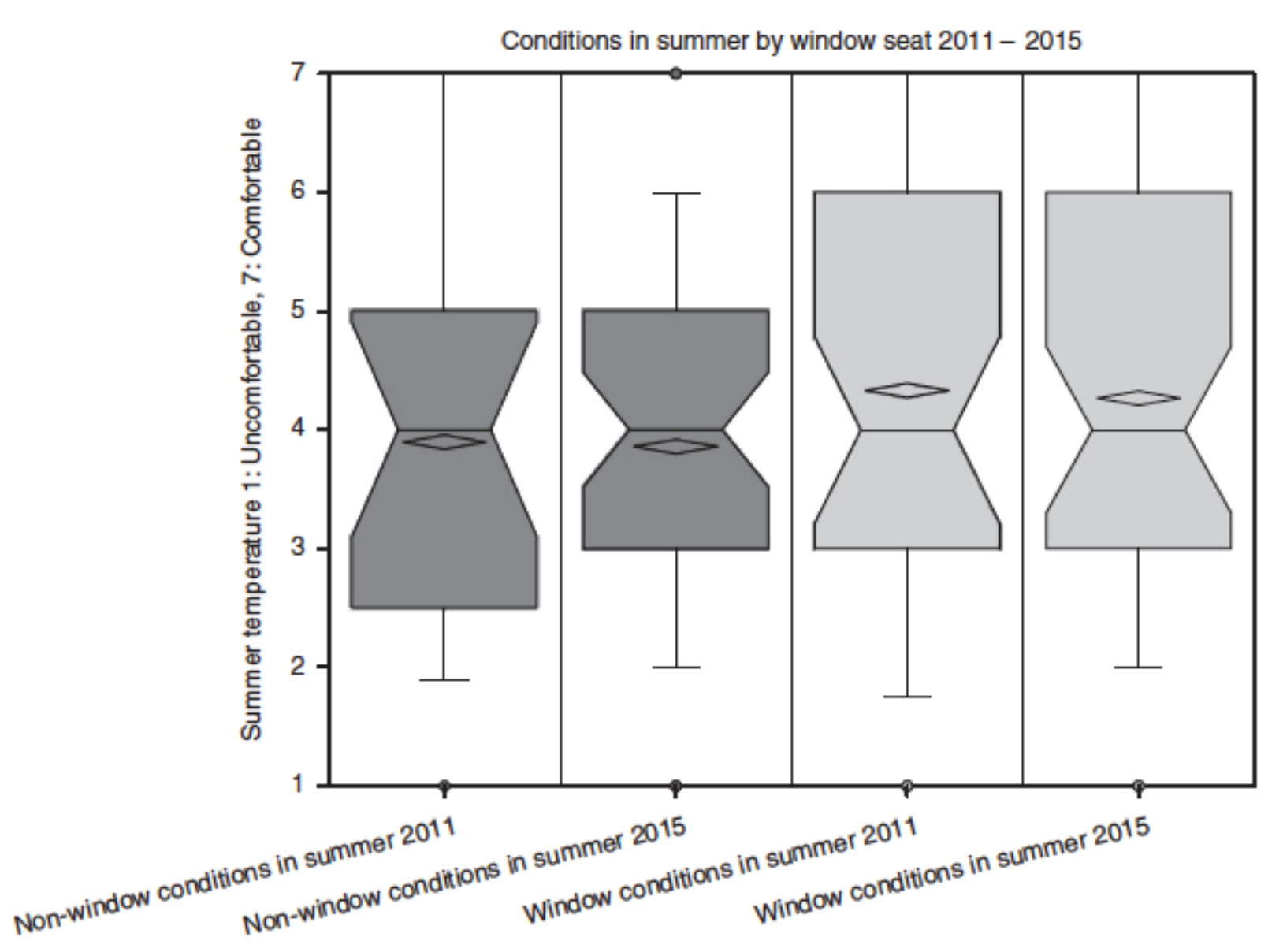

Figure 11: Sample distributions for summer temperature for window and non-window seats in Building A, 2011 and 2015. The distribution of comfort data covers 5th to 95th percentiles with outliers. Mean values are shown as diamonds, and median values by notches in the plots.

Similarly, for perceptions of temperature in winter, Figure 12 shows that window respondents in the 2011 and 2015 surveys reported similar perceptions, with a slight decline in mean scores, although both scores are above scale midpoint. In 2011, the few staff in non-window positions reported a mean score of 5.05; by 2015 this had fallen to a mean score of 3.80 (a statistically different distribution). 


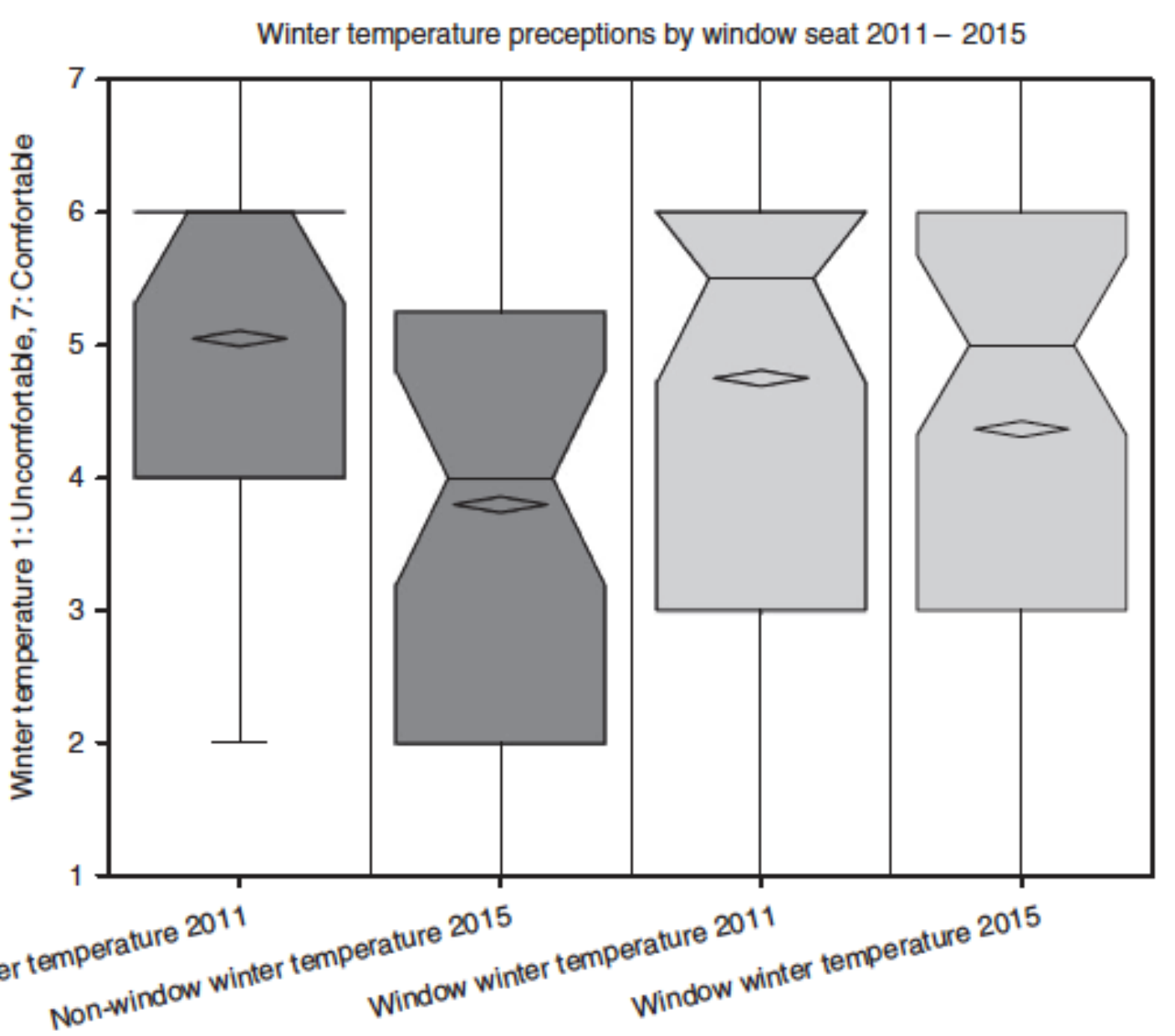

Figure 12: Sample distributions for winter temperature for window and non-window seats in Building A, 2011 and 2015. The distribution of comfort data covers 5th to 95th percentiles with outliers. Mean values are shown as diamonds, and median values by notches in the plots.

The difference compared with window seats in 2015 is smaller as conditions were also perceived by 2015 window seat respondents to have declined. respondents reporting close proximity to a window in both surveys say they are more comfortable overall than those without a window seat, although the distributions in each year overlap and the mean values are not dissimilar (Figure 13). 


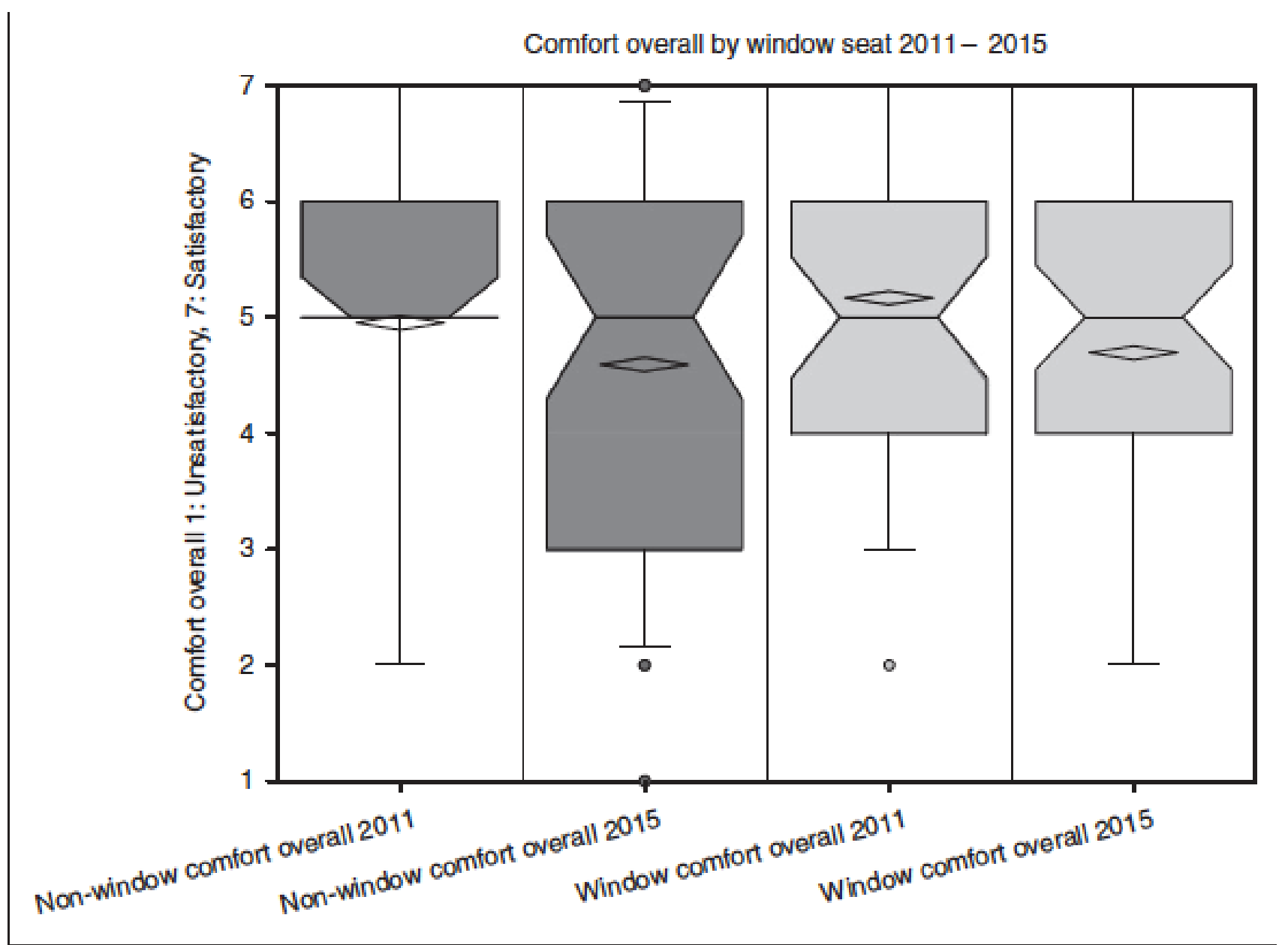

Figure 13: Sample distributions for overall comfort for window and non-window seats in Building A, 2011 and 2015. The distribution of comfort data covers 5th to 95th percentiles with outliers. Mean values are shown as diamonds, and median values by notches in the plots.

Perceptions of natural light in 2011 and 2015 were virtually identical for both window and non-window seat respondents. Non-window seat respondents scored just below the scale of ' 3 ' in both survey years; the availability of natural light may be relatively lower away from a window, but the mean score did not decline (and the distribution did not change) with the doubling of the sample size from 22 to 44 respondents (Table 7). This may be a function of office depth, which is $6.8 \mathrm{~m}$ from window to corridor wall.

Figure 14 shows the outcome variable of perceived productivity. The statistics indicate that respondents in 2011 and 2015 both found a window seat conducive to their productivity. 
Perceived productivity by window seat $2011-2015$

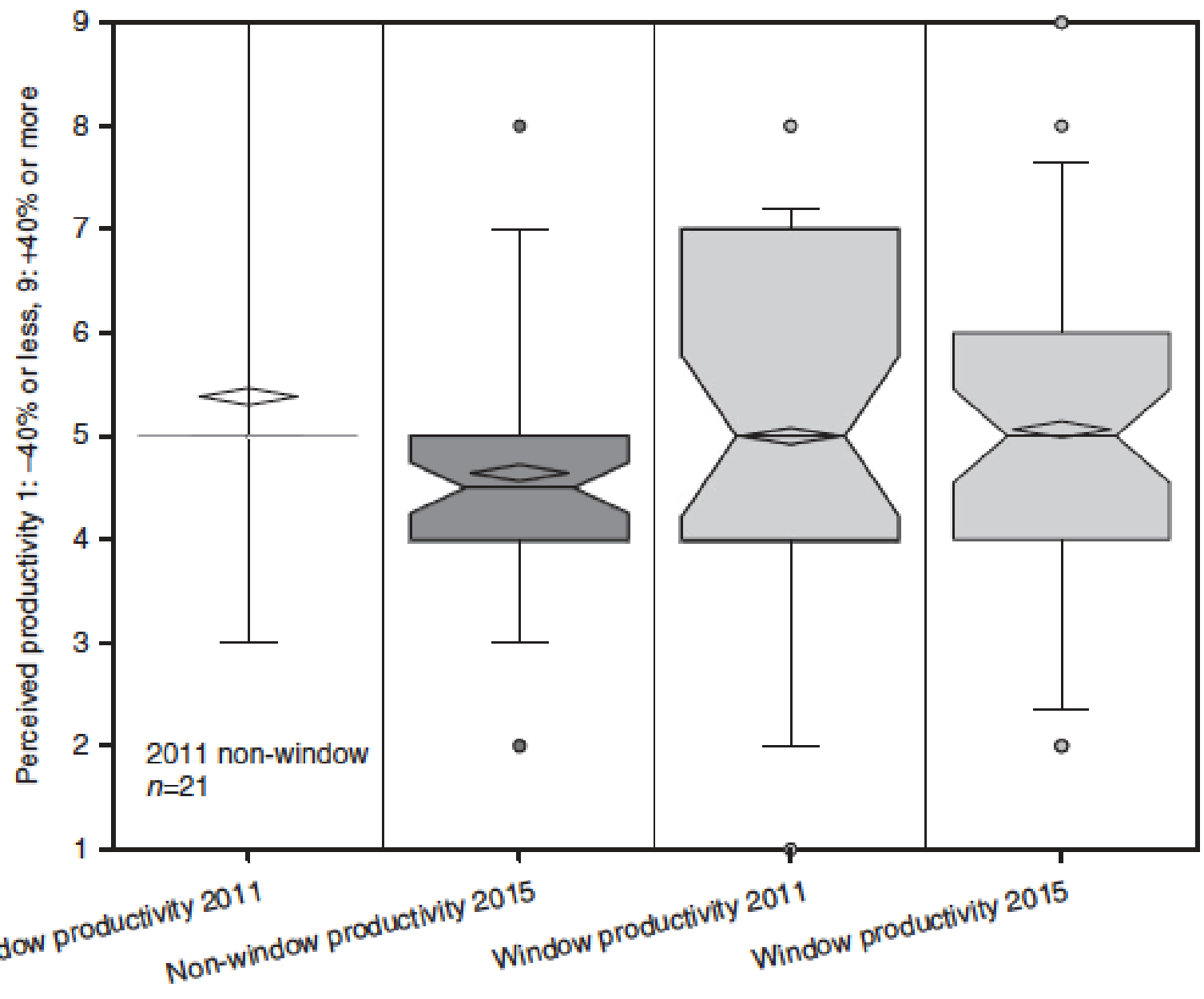

Figure 14: Sample distributions for perceived productivity for window and non-window seats in Building A, 2011 and 2015. The distribution of comfort data covers 5th to 95th percentiles with outliers. Mean values are shown as diamonds, and median values by notches in the plots.

Overall, the response distributions show an increasing trend over the survey period to lower mean comfort scores from those in non-window seats.

Table 7: statistical analysis of window and non-window comfort variables for Building $A$ by window and non-window respondents.

\begin{tabular}{|c|c|c|c|c|c|c|c|}
\hline & \multicolumn{4}{|c|}{ Mean occupant scores (sample size) } & \multicolumn{2}{|c|}{ Two tailed U-Test } & \multirow{3}{*}{$\begin{array}{c}\text { Within } \\
\text { year } \\
\text { statistical } \\
\text { difference } \\
P<0.05\end{array}$} \\
\hline & \multicolumn{2}{|c|}{2011} & \multicolumn{2}{|c|}{2015} & \multirow{2}{*}{$\begin{array}{l}2011 \text { window } \\
\text { /non-window }\end{array}$} & \multirow{2}{*}{$\begin{array}{l}2015 \text { window } \\
\text { /non-window }\end{array}$} & \\
\hline & Window & Non-window & Window & Non-window & & & \\
\hline $\begin{array}{l}\text { Temperature } \\
\text { in summer }{ }^{1}\end{array}$ & $4.25(n=36)$ & $3.38(n=21)$ & $3.72(n=46)$ & $3.37(n=41)$ & 0.1104 & 0.3834 & $\mathrm{~N}$ \\
\hline $\begin{array}{l}\text { Temperature } \\
\text { in winter }{ }^{1}\end{array}$ & $4.75(n=36)$ & $5.05(n=21)$ & $4.37(n=49)$ & $3.80(n=40)$ & 0.5965 & 0.1829 & $\mathrm{~N}$ \\
\hline $\begin{array}{l}\text { Conditions in } \\
\text { summer }^{2}\end{array}$ & $4.33(n=36)$ & $3.89(n=19)$ & $4.27(n=45)$ & $3.86(n=42)$ & 0.4309 & 0.2807 & $\mathrm{~N}$ \\
\hline
\end{tabular}




\begin{tabular}{|l|l|l|l|l|l|l|l|}
\hline $\begin{array}{l}\text { Conditions in } \\
\text { winter }^{2}\end{array}$ & $4.81(n=37)$ & $4.86(n=21)$ & $4.50(n=48)$ & $3.78(n=40)$ & 0.9291 & 0.0634 & $\mathrm{~N}$ \\
\hline Natural light $^{3}$ & $3.68(n=38)$ & $2.95(n=22)$ & $3.49(n=49)$ & $2.98(n=44)$ & 0.1159 & 0.0712 & $\mathrm{~N}$ \\
\hline $\begin{array}{l}\text { Overall } \\
\text { comfort }^{2}\end{array}$ & $5.17(n=36)$ & $4.95(n=21)$ & $4.69(n=49)$ & $4.59(n=44)$ & 0.6671 & 0.7877 & $\mathrm{~N}$ \\
\hline $\begin{array}{l}\text { Productivity } \\
\text { (perceived })^{4}\end{array}$ & $5.00(n=37)$ & $5.38(n=21)$ & $5.06(n=48)$ & $4.64(n=42)$ & 0.6332 & 0.1523 & $\mathrm{~N}$ \\
\hline
\end{tabular}

${ }^{1}$ Scale labels 1: Uncomfortable, 7: Comfortable.

${ }^{2}$ Scale labels 1: Unsatisfactory overall, 7: Satisfactory overall.

${ }^{3}$ Scale labels 1: Too little, 7: Too much.

${ }^{4}$ Scale labels 1: $-40 \%$ or less, $9:+40 \%$ or more.

Table 8: Mann-Whitney U-test scores for Building A (unpaired samples) for functional variables.

\begin{tabular}{|c|c|c|c|c|c|c|c|}
\hline \multirow{2}{*}{$\begin{array}{l}\text { Perceived } \\
\text { characteristics }\end{array}$} & \multirow{2}{*}{$\begin{array}{l}1998 \text { mean } \\
\text { scores }\end{array}$} & \multirow{2}{*}{$\begin{array}{l}2011 \text { mean } \\
\text { scores }\end{array}$} & \multirow{2}{*}{$\begin{array}{l}2015 \text { mean } \\
\text { scores }\end{array}$} & \multicolumn{2}{|c|}{ Two-tailed U-test } & \multicolumn{2}{|c|}{$\begin{array}{c}\text { Statistically } \\
\text { different at } P<0.05\end{array}$} \\
\hline & & & & $2011 / 1998$ & $2011 / 2015$ & 1998/2011 & $2011 / 2015$ \\
\hline Cleaning & $\mathrm{N} / \mathrm{A}$ & $6.36(n=59)$ & $5.76(n=94)$ & $\mathrm{N} / \mathrm{A}$ & 0.0026 & $\mathrm{~N} / \mathrm{A}$ & $\mathrm{Y}$ \\
\hline Meeting Rooms & $\mathrm{N} / \mathrm{A}$ & $3.84(n=58)$ & $4.47(n=91)$ & $\mathrm{N} / \mathrm{A}$ & 0.1000 & $\mathrm{~N} / \mathrm{A}$ & $\mathrm{N}$ \\
\hline Storage & $\mathrm{N} / \mathrm{A}$ & $4.75(n=60)$ & $4.07(n=94)$ & $\mathrm{N} / \mathrm{A}$ & 0.0286 & $\mathrm{~N} / \mathrm{A}$ & $Y$ \\
\hline Space use & $N / A$ & $4.97(n=58)$ & $4.96(n=91)$ & $\mathrm{N} / \mathrm{A}$ & 0.7129 & $\mathrm{~N} / \mathrm{A}$ & $\mathrm{N}$ \\
\hline $\begin{array}{l}\text { Artificial light (7: too } \\
\text { much) }\end{array}$ & $3.28(n=39)$ & $4.13(n=60)$ & $4.51(n=92)$ & 0.0033 & 0.0803 & $\mathrm{Y}$ & $\mathrm{N}$ \\
\hline $\begin{array}{l}\text { Noise overall (7: } \\
\text { satisfactory) }\end{array}$ & $5.05(n=40)$ & $4.32(n=60)$ & $4.71(n=94)$ & 0.0446 & 0.1739 & Y & $\mathrm{N}$ \\
\hline
\end{tabular}

The scores for functional variables in Building A show satisfaction with artificial light and noise, with occupants reporting slightly too much electric lighting and a decline in satisfaction with noise conditions. While perception of cleanliness fell statistically in 2015 compared with 2011, the mean score is still high.

To gain insight into the possible causes of these changed perspectives, samples were split by office type to determine whether the change to more open-plan working might be the reason. The results are shown in Table 9. The data reveal that the staff in open-plan spaces perceive storage and the use of space to be statistically lower than occupants in non open-plan spaces. In Table 10, mean scores for the outcome variables of comfort, perceived productivity and perceived health are also lower in open-plan spaces.

Table 9: Mann-Whitney U-test scores for Building A (unpaired samples) for functional variables by work group size, 2015.

\begin{tabular}{|l|c|c|c|c|c|c|}
\hline $\begin{array}{l}\text { Comfort } \\
\text { variable }\end{array}$ & $\begin{array}{c}\text { Cellular, shared } \\
\text { and non-office }\end{array}$ & $\begin{array}{c}\text { Open-plan } \\
\text { offices }\end{array}$ & $\begin{array}{c}\text { Mean scores, } \\
\text { cellular \& shared }\end{array}$ & $\begin{array}{c}\text { Mean scores, } \\
\text { open-plan }\end{array}$ & $\begin{array}{c}\text { Two-tailed } \\
\text { U-test }\end{array}$ & $\begin{array}{c}\text { Significant at } \\
\text { P<0.05 }\end{array}$ \\
\hline Design & $n=46$ & $n=48$ & 5.39 & 4.90 & 0.0213 & Y \\
\hline Needs & $n=46$ & $n=47$ & 5.33 & 4.87 & 0.0453 & Y \\
\hline Meeting rooms & $n=44$ & $n=47$ & 4.32 & 4.62 & 0.4411 & $\mathrm{~N}$ \\
\hline Space use & $n=43$ & $n=48$ & 5.30 & 4.65 & 0.0180 & $\mathbf{Y}$ \\
\hline Storage & $n=46$ & $n=48$ & 4.93 & 3.25 & 0.0001 & $\mathbf{Y}$ \\
\hline
\end{tabular}


${ }^{1}$ Mann-Whitney U-Test for unpaired samples.

Table 10: Outcome variables for Building A open-plan offices compared with cellular and non-office spaces.

\begin{tabular}{|l|c|c|c|c|c|c|}
\hline Comfort variable & $\begin{array}{c}\text { Cellular, shared } \\
\text { \& non-office }\end{array}$ & $\begin{array}{c}\text { Open } \\
\text { plan }\end{array}$ & $\begin{array}{c}\text { Mean score } \\
\text { cellular \& shared }\end{array}$ & $\begin{array}{c}\text { Mean scores, } \\
\text { open-plan }\end{array}$ & $\begin{array}{c}\text { Two-tailed } \\
\text { U-test }\end{array}$ & $\begin{array}{c}\text { Significant } \\
\text { at P<0.05 }^{1}\end{array}$ \\
\hline Overall comfort & $n=46$ & $n=47$ & 4.98 & 4.32 & 0.0302 & $\mathbf{Y}$ \\
\hline Health (perceived) & $n=46$ & $n=48$ & 4.09 & 3.27 & 0.0004 & Y \\
\hline Productivity (perceived) & $n=43$ & $n=47$ & 5.44 & 4.34 & 0.0005 & $\mathbf{Y}$ \\
\hline
\end{tabular}

${ }^{1}$ Mann-Whitney U-Test for unpaired samples.

\subsection{Detailed results: Building $B$}

The characteristics for building B in 2006 and 2015 were captured in tables for the context categories. As the IT department had not moved in the nine years between surveys it was possible to conduct a like-for-like comparison over that period.

Table 11: Building B primary level nest - physical and occupancy characteristics.

\begin{tabular}{|c|c|c|c|c|}
\hline \multirow{2}{*}{ Characteristic } & \multirow{2}{*}{ Source } & \multicolumn{2}{|c|}{ Context } & \multirow[t]{2}{*}{$\begin{array}{l}\text { Statistical } \\
\text { change }\end{array}$} \\
\hline & & 2006 & 2015 & \\
\hline Orientation & Record drawings & South-West & South-West & $\mathrm{N}$ \\
\hline Storeys & Record drawings & 2 & 2 & $\mathrm{~N}$ \\
\hline Floor area & Record drawings & $\begin{array}{c}7350 \mathrm{~m}^{2}(\mathrm{GIA}) \\
5875 \mathrm{~m}^{2} \text { (offices) }\end{array}$ & $\begin{array}{c}7350 \mathrm{~m}^{2}(\mathrm{GIA}) \\
5875 \mathrm{~m}^{2} \text { (offices) }\end{array}$ & $\mathrm{N}$ \\
\hline Ventilation type & Record drawings & $\begin{array}{l}\text { Mixed mode, manual } \\
\text { windows and vents }\end{array}$ & $\begin{array}{l}\text { Mixed mode, automatic } \\
\text { windows and vents }\end{array}$ & $\mathbf{Y}$ \\
\hline Control strategy & NT Records & Local control & Central control & $\mathbf{Y}$ \\
\hline Spatial type & Record drawings & Open-plan & Open-plan & $\mathrm{N}$ \\
\hline Plan depth & Record drawings & & & $\mathrm{N}$ \\
\hline $\begin{array}{l}\text { Maximum distance to beverage } \\
\text { point }\end{array}$ & Drawing take-off & $35 \mathrm{~m}$ & $35 \mathrm{~m}$ & $\mathrm{~N}$ \\
\hline Maximum distance to toilet & Drawing take-off & $38 \mathrm{~m}$ & $38 \mathrm{~m}$ & $\mathrm{~N}$ \\
\hline $\begin{array}{l}\text { Maximum distance to vertical } \\
\text { circulation }\end{array}$ & Drawing take-off & & & $\mathrm{N} / \mathrm{A}$ \\
\hline $\begin{array}{l}\text { Maximum distance to main } \\
\text { entrance }\end{array}$ & Drawing take-off & $69 \mathrm{~m}$ & $69 \mathrm{~m}$ & $\mathrm{~N}$ \\
\hline Atriums and courtyards & Record drawings & 3 & 3 & $\mathrm{~N}$ \\
\hline Occupant seats & Recorded & $\begin{array}{l}423 \text { (design) } \\
426 \text { (move in) }\end{array}$ & 586 & $Y(+38.5 \%)$ \\
\hline $\begin{array}{l}\text { Overall workspace density } \\
\text { (office area/seats) }^{1}\end{array}$ & Recorded & $1 / 14 \mathrm{~m}^{2}$ & $1 / 10 \mathrm{~m}^{2}$ & Y (-28\%) \\
\hline $\begin{array}{l}\text { Persons per single WC (Whole } \\
\text { building average) }\end{array}$ & Drawing take-off & $\begin{array}{c}35 \text { (design) } \\
39 \text { (by desks) }\end{array}$ & $\begin{array}{c}48 \text { (Desks) } \\
54 \text { (Max) }\end{array}$ & $Y(+37-54 \%)$ \\
\hline Male occupants per urinal ${ }^{3}$ & Drawing take-off & 23 & $28(31)$ & $\mathrm{Y}(23 \%)$ \\
\hline Age profile $(n<30 / n>30)$ & BUS Response & $63 / 179$ & $78 / 281$ & \\
\hline $\begin{array}{l}\text { Gender split (percentage } \\
\text { female/male) })^{2}\end{array}$ & BUS Response & $62 / 38$ & $62 / 38$ & $\mathrm{~N}$ \\
\hline $\begin{array}{l}\text { Maximum full-time occupants } \\
(\text { approx })^{4}\end{array}$ & Recorded & 475 & 650 & $\mathbf{Y}$ \\
\hline
\end{tabular}

${ }^{1}$ Derived using BUS respondents segregated by gender as a proxy for the total occupancy.

${ }^{2}$ Actuals unknown due to high numbers of part-time workers attending from other offices. 
${ }^{3}$ Note that the actual numbers are survey respondents only. The percentage increase is the important metric.

3 Overall densities, with no correction for utilisation levels. January 2013 recorded at 630 staff for 495 workstations.

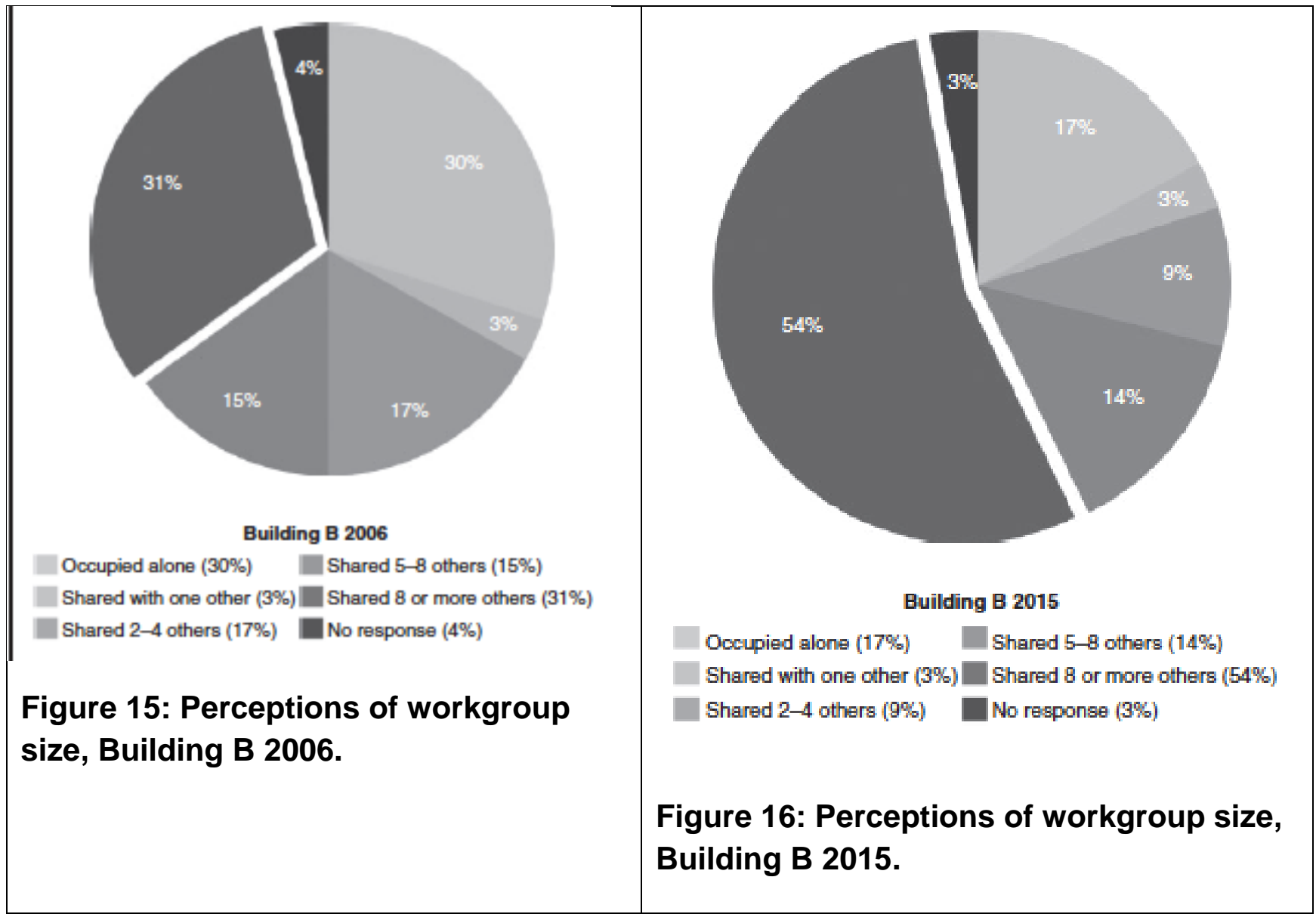

In 2006, 31\% of occupants perceived themselves working in an area shared by eight or more (Figure 15), with 30\% reporting being in a work area alone. In 2015, 54\% perceived themselves to be in workgroups of eight or more (Figure 16). The second level context (reported characteristics) shows significant falls in perceptions of all personal environmental control variables (Table 12). Of the five variables, ventilation has shown the greatest movement. These statistics match the change in control strategy shown in Table 12.

Table 12: Building B second level nest - reported characteristics. Key changes over time shown in red.

\begin{tabular}{|r|c|c|c|c|}
\hline \multirow{2}{*}{ Environmental control variables $^{3}$} & \multicolumn{4}{|c|}{ Movement between mean scores (1=No control, 7=Full control) } \\
\cline { 2 - 5 } & $\mathbf{2 0 0 6}$ & $\mathbf{2 0 1 5}$ & Two-tailed U-test $^{4}$ & Significant at $\mathbf{P}<\mathbf{0 . 0 5}^{\mathbf{Y}}$ \\
\hline Heating & 2.08 & 1.28 & 0.0001 & $\mathbf{Y}$ \\
\hline Cooling & 2.43 & 1.51 & 0.0001 & $\mathbf{Y}$ \\
\hline Ventilation & 3.01 & 1.77 & 0.0001 & $\mathbf{Y}$ \\
\hline Lighting & 2.44 & 1.76 & 0.0001 & $\mathbf{Y}$ \\
\hline Noise & 1.74 & 1.35 & 0.0001 & N/A \\
\hline Controls usability & N/A & 3.02 & N/A & \\
\hline
\end{tabular}

${ }^{1}$ Based on 243 responses in 2006, 361 in 2015.

${ }^{2}$ Means of respondent perceptions on 1-7 scale (Scale: 1 no control, 7 full control). 
${ }^{3}$ Mann-Whitney unpaired samples non-parametric U-test (two-tailed).

${ }^{4} 2015$ survey only, mean scores. (Scale: $1=$ very poor, 7 = very good).

Table 13 shows tests for statistical differences for seasonal variables in Building B. Tests were conducted for the building overall between 2006 and 2015. Occupants' perceptions of thermal and air quality conditions in summer and winter are statistically different between 2006 and 2015. While perceptions of summer temperature have improved overall, the female population (62\% in both years) reported significantly greater thermal and air quality discomfort in winter compared with males in both years.

Table 13: Building B third level context, main seasonal contexts (BUS thermal and air quality perceptions).

\begin{tabular}{|c|c|c|c|c|c|c|c|c|c|}
\hline \multirow[t]{2}{*}{ Factor } & \multicolumn{2}{|c|}{$\begin{array}{c}\text { Sample, overall } \\
\text { population }\end{array}$} & \multicolumn{2}{|c|}{$\begin{array}{l}\text { Mean } \\
\text { scores }\end{array}$} & \multirow{2}{*}{$\begin{array}{c}\text { Two-tailed } \\
\text { U-test } \\
\text { results }\end{array}$} & \multicolumn{2}{|c|}{$\begin{array}{l}\text { Two-tailed U-test } \\
\text { results by gender }\end{array}$} & \multirow{2}{*}{$\begin{array}{c}\text { Overall } \\
\text { significance } \\
P<0.05\end{array}$} & \multirow{2}{*}{$\begin{array}{c}\text { Gender } \\
\text { significance } \\
P<0.05\end{array}$} \\
\hline & $2006 n$ & $2015 n$ & 2006 & 2015 & & 2006 & 2015 & & \\
\hline $\begin{array}{l}\text { Temperature in } \\
\text { summer }\end{array}$ & 197 & 306 & 3.58 & 4.19 & 0.0001 & $0.0623(\mathrm{M})$ & 0.8057 & $\mathbf{Y}$ & $\mathrm{N}$ \\
\hline $\begin{array}{l}\text { Temperature in } \\
\text { winter }\end{array}$ & 222 & 328 & 4.39 & 3.80 & 0.0001 & $0.0150(F)$ & $0.0001(F)$ & $\mathbf{Y}$ & $\mathbf{Y}$ \\
\hline $\begin{array}{l}\text { Conditions in } \\
\text { summer }\end{array}$ & 191 & 306 & 3.88 & 4.16 & 0.0398 & $\mathrm{~N} / \mathrm{A}$ & $<0.2540$ & $\mathbf{Y}$ & $\mathrm{N}$ \\
\hline $\begin{array}{l}\text { Conditions in } \\
\text { winter }\end{array}$ & 224 & 328 & 4.47 & 3.98 & 0.0005 & $0.0073(F)$ & $0.0002(F)$ & $\mathbf{Y}$ & $\mathbf{Y}$ \\
\hline Natural light & 238 & 355 & 3.99 & 4.15 & 0.0611 & $\mathrm{~N} / \mathrm{A}$ & $\mathrm{N} / \mathrm{A}$ & $\mathrm{N}$ & $\mathrm{N} / \mathrm{A}$ \\
\hline $\begin{array}{l}\text { Glare sun and } \\
\text { sky }\end{array}$ & 238 & 355 & 3.30 & 3.51 & 0.1097 & $\mathrm{~N} / \mathrm{A}$ & $\mathrm{N} / \mathrm{A}$ & $\mathrm{N}$ & $\mathrm{N} / \mathrm{A}$ \\
\hline
\end{tabular}

${ }^{1}$ Mann-Whitney non-parametric un-paired samples U-Test (two-tailed).

${ }^{2}$ M: Male, F: Female. Kruskal-Wallis non-parametric un-paired samples $\mathrm{H}$-Test. Tied $\mathrm{P}$ values quoted only, as the population sample contains ties (i.e. identical whole integer scores on the 1-7 scale).

Occupant perceptions for the functional variables in building B overall are shown in Table 14. Satisfaction with meeting rooms has shown the biggest decline. The large drop in satisfaction with meeting room spaces in 2015 compared with 2006 is a combination of a shortage of meeting room space, coupled to ongoing problems with the room booking system, reported by both occupants and the facilities manager. It was observed by the researcher and that some meeting rooms are used as cellular office space, reportedly by teams whose work requires privacy. Staff are therefore forced to use the atrium café for meetings, particularly at lunchtime, which then competes with those who wish to use the atrium for their lunch break. Evidence was provided by the facilities manager, and widely reported in occupants' free text survey comments.

The higher numbers using the building has created pressure on storage, particularly for hotdesk areas. Perception of the building's effective use of space has dropped statistically, but satisfaction is still above scale midpoint. 


\section{Table 14: Perception changes for functional variables in Building B overall between 2006 and 2015.}

All outcome variables (Table 15) have declined statistically since 2006, although only perceived health has fallen below the scale midpoint of ' 4 '. The drop in the mean scores are marginal but the distribution of responses has have shifted enough to be statistically different. Given the strain placed on the building's functional factors, the continuing high perception of the building's comfort conditions suggests that the building has a high amount of redundancy in other areas that compensates for other shortcomings. This supposition was tested by studying the response scores from IT department, which operates at a much higher density in 2015 than other parts of the building.

Table 15: Building B: results of the outcome variables.

\begin{tabular}{|l|c|c|c|c|c|c|}
\hline Characteristic & $\mathbf{2 0 0 6} n$ & $\mathbf{2 0 1 5} n$ & $\begin{array}{c}\mathbf{2 0 0 6} \text { mean } \\
\text { scores }\end{array}$ & $\begin{array}{c}\mathbf{2 0 1 5} \\
\text { mean scores }\end{array}$ & $\begin{array}{c}\text { U Test } \\
\mathbf{P}<\mathbf{0 . 0 5}\end{array}$ & $\begin{array}{c}\text { Significant } \\
\text { at } \mathbf{P}<\mathbf{0 . 0 5}\end{array}$ \\
\hline Overall comfort & 231 & 354 & 4.99 & 4.75 & 0.0337 & $\mathrm{Y}$ \\
\hline Health (perceived) & 230 & 354 & 4.16 & 3.71 & 0.0001 & $\mathrm{Y}$ \\
\hline Productivity (perceived) & 216 & 343 & 5.02 & 4.80 & 0.0279 & $\mathrm{Y}$ \\
\hline
\end{tabular}

${ }^{1}$ Mann-Whitney non-parametric un-paired samples U-Test; Significance P $<\square \square \square \square \square$

Conditions in the IT department were studied to determine whether there are pockets of dissatisfaction related to local high density. Statistical tests were performed on a subset formed by the populations of the IT department in 2006 and 2015. Staff numbers had risen from 86 to 128 while the departmental boundaries had stayed the same. This meant that occupant density had risen from an average of one person per $8 \mathrm{~m}^{2}$ to one person per 4.4 $\mathrm{m}^{2}-$ a much tighter density than in the building overall.

The 2015 BUS included a question on whether staff believe there were too many or too few people in their work environment. This was intended as a measure of perceived density that could be compared with the measured density. The response distributions are shown as histograms in Figures 17 and 18. The density perceptions show a marked skew to 'too many' people compared with perceptions in the building overall. Note that the median value for the IT department is two integers higher. This corroborates the spatial measurements that indicate density is far tighter than BCO norms.

Table 14: Perception changes for functional variables in Building B overall between 2006 and 2015.

\begin{tabular}{|l|c|c|c|c|c|c|}
\hline Comfort variable & $\mathbf{2 0 0 6} n$ & $\mathbf{2 0 1 5} n$ & $\begin{array}{c}\text { Mean scores } \\
\mathbf{2 0 0 6}\end{array}$ & $\begin{array}{c}\text { Mean scores } \\
\mathbf{2 0 1 5}\end{array}$ & $\begin{array}{c}\text { Two-tailed } \\
\text { U-test }\end{array}$ & $\begin{array}{c}\text { Statistically different } \\
\text { at } \mathbf{P}<\mathbf{0 . 0 5}\end{array}$ \\
\hline Meeting rooms & 229 & 347 & 5.02 & 3.34 & 0.0001 & $\mathrm{Y}$ \\
\hline Space use effectiveness & 238 & 355 & 5.25 & 4.70 & 0.0001 & $\mathrm{Y}$ \\
\hline Storage & 237 & 349 & 4.13 & 3.87 & 0.0950 & $\mathrm{~N}$ \\
\hline
\end{tabular}




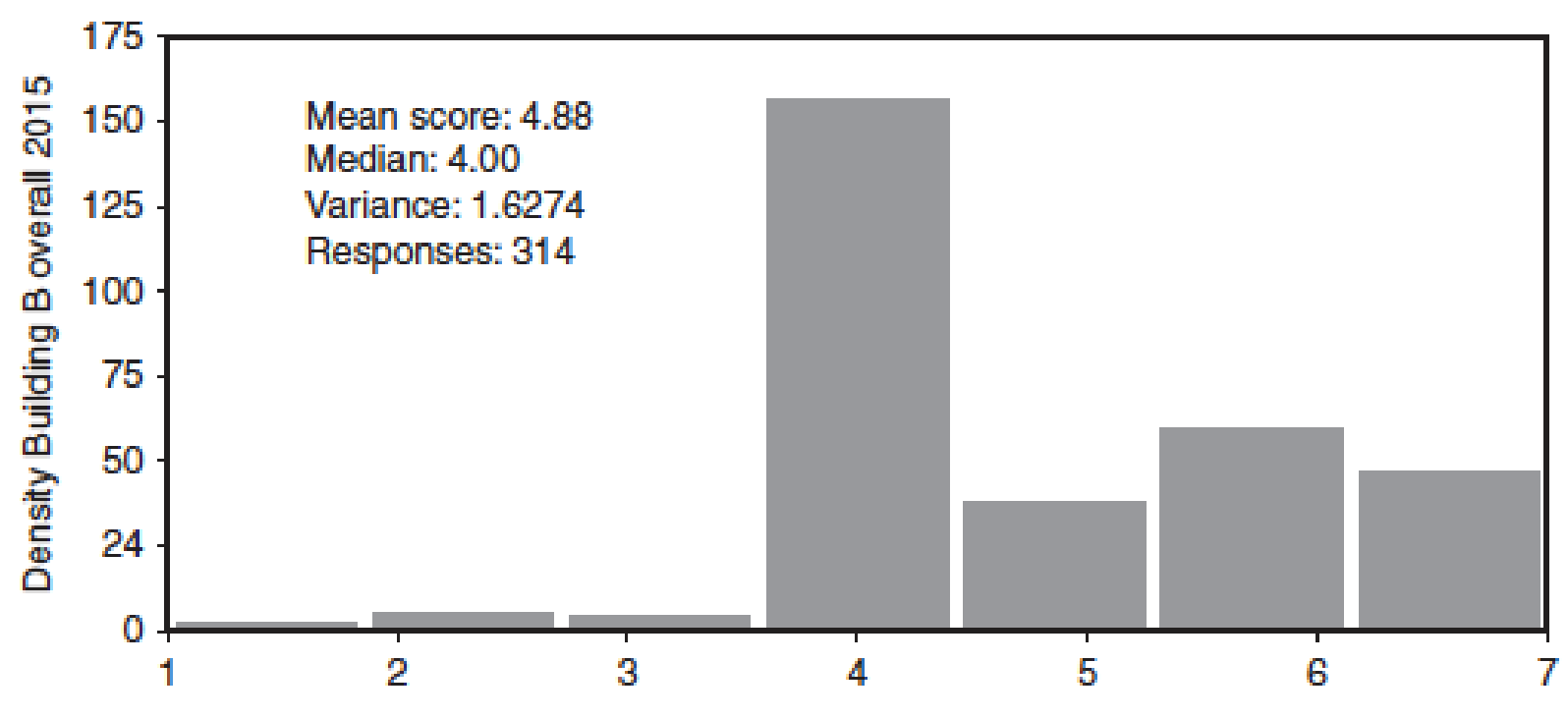

Perceptions of workplace density: $1=$ too few, 7 = too many

Figure 17: Occupant density perceptions in 2015, Building B overall.

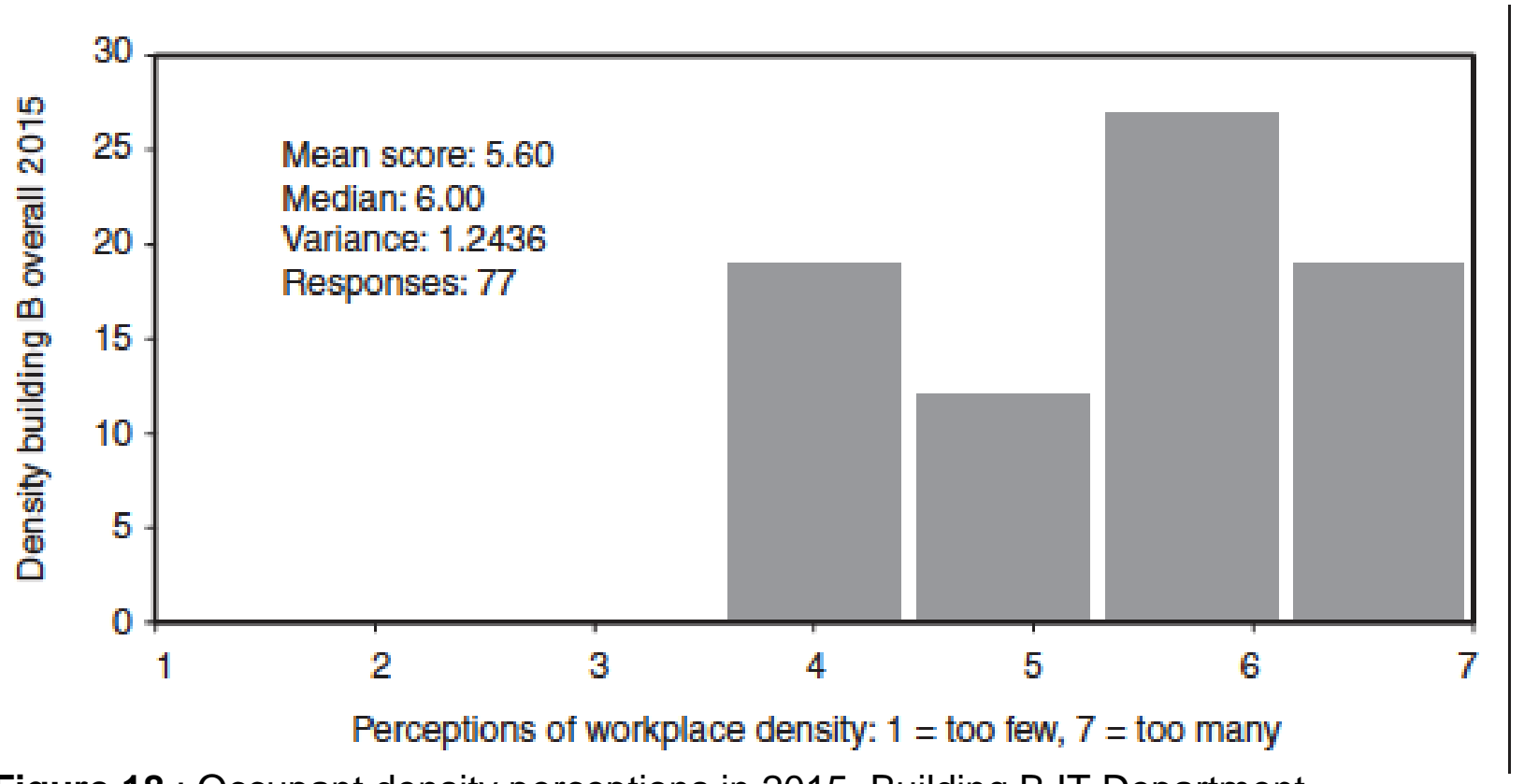

Figure 18 : Occupant density perceptions in 2015, Building B IT Department.

The density results (physical and perceived) in the IT department are consistent with the statistical fall in perceptions of space use effectiveness (Table 16), suggesting an association with the decline in the outcome variables of comfort, and perceived health and productivity (Table 15). Analysis of the IT department data found no statistical differences between 2006 and 2015 for seasonal comfort variables, so the environmental conditions can be discounted as the principal fall in staff perceptions of comfort and productivity. Note that space effectiveness in the IT department was scored above scale midpoint in 2015, so a crisis of discomfort does not seem to have been reached. 
Table 16: Mann-Whitney U-test scores (unpaired samples) for Building B, IT department.

\begin{tabular}{|l|c|c|c|c|c|c|}
\hline Comfort variable & $\begin{array}{c}\mathbf{2 0 0 6} \\
\text { Sample }\end{array}$ & $\begin{array}{c}\mathbf{2 0 1 5} \\
\text { Sample }\end{array}$ & $\begin{array}{c}\mathbf{2 0 0 6} \text { mean } \\
\text { scores }\end{array}$ & $\begin{array}{c}\mathbf{2 0 1 5} \text { mean } \\
\text { scores }\end{array}$ & $\begin{array}{c}\text { U Test P } \\
<\mathbf{0 . 0 5}\end{array}$ & $\begin{array}{c}\text { Significant } \\
\text { at P } \mathbf{0 . 0 5}\end{array}$ \\
\hline Meeting rooms & 35 & 86 & 5.14 & 3.40 & $<0.0001$ & Y \\
\hline Space use in building & 38 & 87 & 5.21 & 4.34 & $<0.0015$ & Y \\
\hline Storage & 38 & 86 & 4.24 & 3.63 & $<0.0351$ & $\mathbf{Y}$ \\
\hline
\end{tabular}

${ }^{1}$ Mann-Whitney non-parametric un-paired samples U-Test.

Perceptions of reduced productivity and health in the IT department are nudging significance at $\mathrm{P}<0.05$ (Table 17). This suggests other factors may be contributing to the perceived decline. Although the 2006 sample is $30 \%$ of the 2015 sample, the response rates were high in both cases so the samples are representative.

Although density perception data is not available for 2006, the comparison between the functionality scores for Building B overall (Figure 19) and the scores for the IT department (Figure 20) show an association between increased density and lower satisfaction with needs met and space use effectiveness. A causal link is not proven, but the relationship is logical. It suggests that functional variables are just as important in determining occupant satisfaction as the environmental (seasonal) variables.

Table 17: Building B IT department outcome variables (BUS perceptions).

\begin{tabular}{|l|c|c|c|c|c|c|}
\hline Characteristic & $\mathbf{2 0 0 6} \boldsymbol{n}$ & $\mathbf{2 0 1 5} \boldsymbol{n}$ & $\begin{array}{c}\mathbf{2 0 0 6} \\
\text { mean }\end{array}$ & $\begin{array}{c}\mathbf{2 0 1 5} \\
\text { mean }\end{array}$ & $\begin{array}{c}\mathbf{P}<\mathbf{0 . 0 5} \text { (Two } \\
\text { tailed) }\end{array}$ & $\begin{array}{c}\text { Significant at } \mathbf{P} \\
<\mathbf{0 . 0 5}\end{array}$ \\
\hline Overall comfort & 38 & 86 & 4.68 & 4.64 & 0.6764 & $\mathrm{~N}$ \\
\hline Health (perceived) & 38 & 86 & 4.11 & 3.74 & 0.0507 & $\mathrm{~N}$ \\
\hline Productivity (perceived) & 38 & 86 & 5.18 & 4.72 & 0.0605 & $\mathrm{~N}$ \\
\hline
\end{tabular}

${ }^{1}$ Mann-Whitney non-parametric un-paired samples U-Test. 


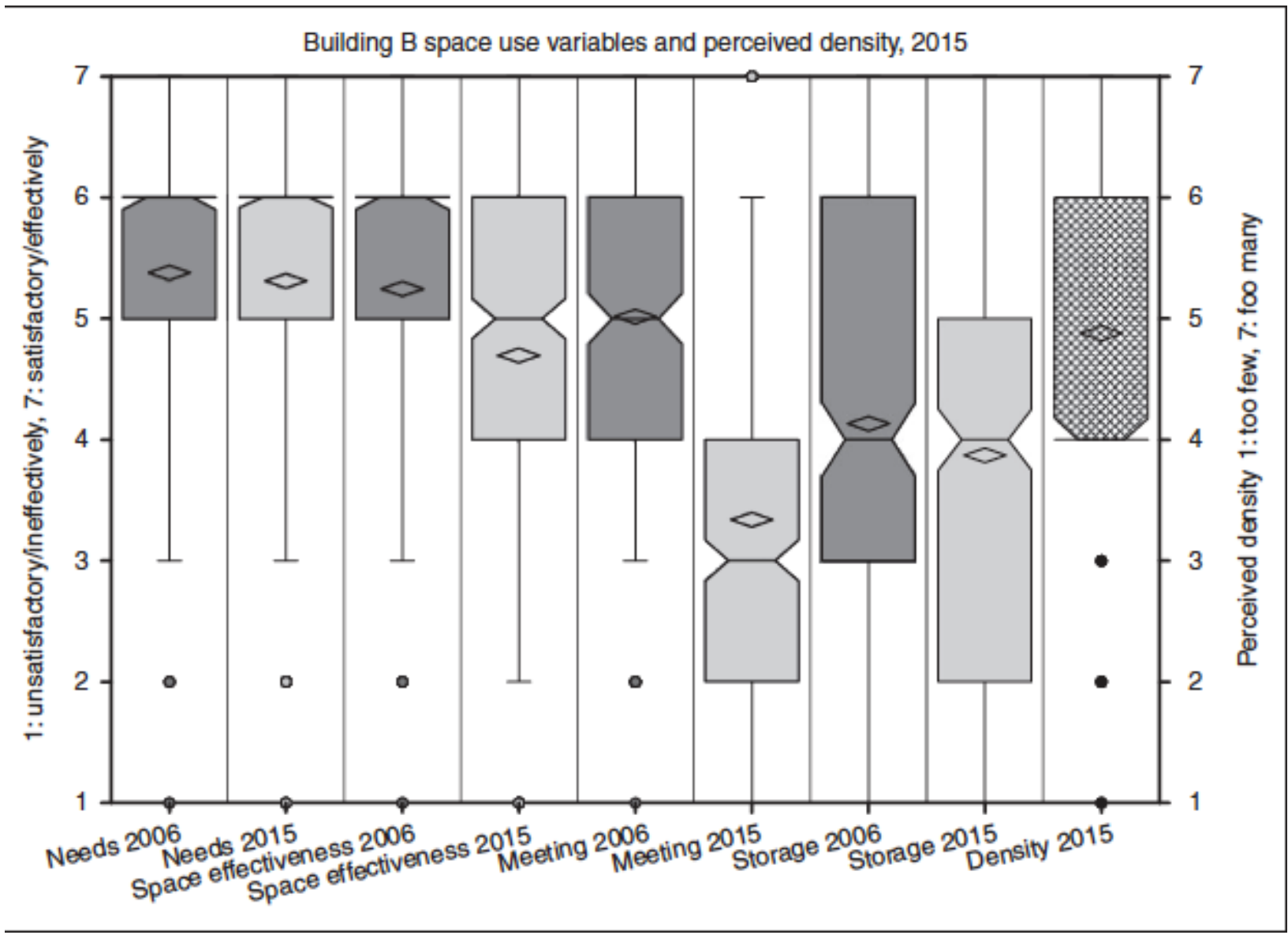

Figure 19: Movement in functionality and space use variables in Building B. Data shown 5th and 95th percentiles with outliers. Diamonds indicate means. Line through variable shows the modal value (the score that occurs most frequently. 
Building B IT department functional variables $2006 \& 2015$

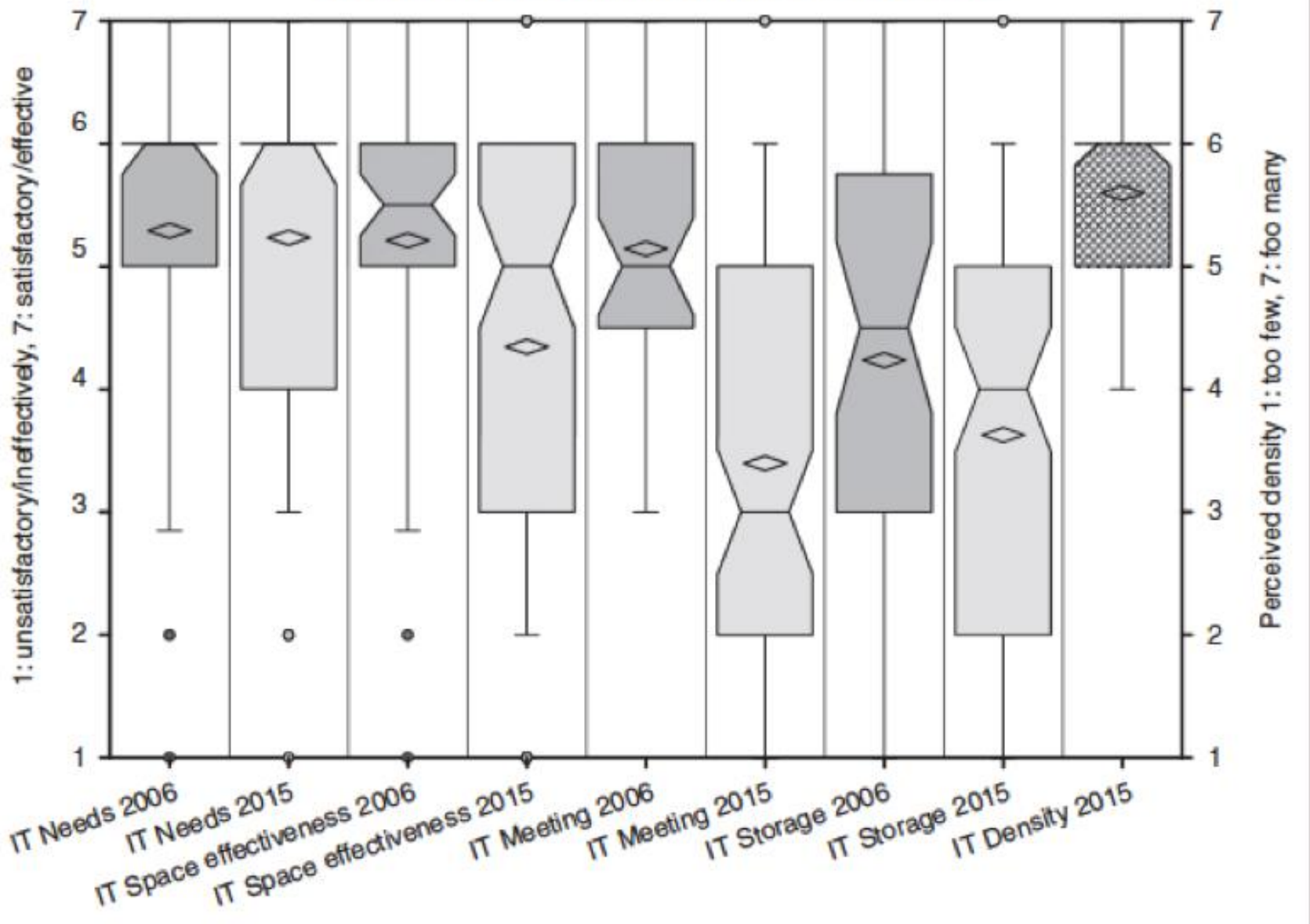

Figure 20: Movement in functionality and space use variables in Building B IT department, with 2015 density perceptions. Data shown 5th and 95th percentiles with outliers. Notched line shows the mode.

\subsection{Discussion}

For building $A$, the declining trend in occupant satisfaction has been traced over three surveys spanning 18 years, while for Building $A$ the trend was for two surveys over nine years. In both cases, movement in occupant perception of comfort variables could be associated with, and sometimes explained by, changes in each building's physical context. The statistical analysis shows that the perceptions of occupants are often not statistically different over time unless something has materially changed to motivate occupants to score lower or higher on the survey scale. Where such changes have occurred, it has been possible to associate perceptions with the changed physical parameters. Because of this relationship, it is postulated that occupants' perceptions of a building may be fixed at the outset, with satisfaction scores then moving relative to the original scores depending on the nature and degree of the physical and operational changes.

Both buildings started out with a particular arrangement of summary BUS comfort scores. The descriptive statistics have a remarkable symmetry over the passage of time that 
appear to be distinct to each building - hence the use of the term 'building signature'. Although the perception scores have moved, the relationship of the variable scores is remarkably similar in both cases. The symmetry of the decline of most variables in Building A has been associated with, or explained by, the changes that have taken place. This suggests that it may be possible to associate movement in perceptions of comfort and productivity with operational decisions in buildings. It is believed that the form of context mapping attempted in the research has identified many of the important parameters, although more research is needed to determine the relative importance of the factors, their relationship, and indeed to identify any parameters that may be missing.

For Building A, the shift from wholly cellular and team-based offices to more open-plan working for around half of the building's occupants has led to a marked decline in occupant satisfaction. A higher percentage of occupants perceive themselves to be working in larger workgroups, which is consistent with the perceived and actual higher densities. A decline in satisfaction is evident when the BUS response samples were separated by type of office and by window and non-window seats. Statistical differences show markedly in a drop in satisfaction particularly with functional variables such as space use effectiveness and storage.

For Building $A$, results indicate that the primary cause of a decline in comfort conditions in 2015 compared with previous BUS assessments is a combination of increased open-plan working, higher density specifically in recently created open-plan office areas, and a reduction in proximity to windows. This is concomitant with the perception of larger workgroups, a perceived loss of control over ventilation and lighting, and a reported loss of control over noise sources. The shift from cellular to shared and open-plan offices by nearly $28 \%$ has also been shown to be associated with lower occupant satisfaction compared with the building's former office layout. Statistical analysis of open-plan areas in the building shows a statistical decline in satisfaction with control and space use variables, with lower perceptions of health and productivity in those areas.

While building $A$ is still performing acceptably, satisfaction with conditions in open-plan areas has dropped significantly from an original exemplary level of performance. While the building is satisfying the owner's operational requirements, the removal of comfort factors that people once valued highly in the building - e.g. cellular space, a window seat, smaller workgroups, local storage, and local control over environmental conditions - has led to a marked decline in perceived comfort, productivity and health. That the building still performs acceptably (in terms of perceptions expressed numerically in the BUS survey system) is a credit to the robustness of the original design. However, the decline suggests that the carrying capacity of the building may be being exceeded before any physical limits are being reached.

The findings from Building B show evidence of a building with a higher population than assumed at design. While the building still performs well on a range of comfort variables, its performance from the perspective of the occupants has declined, particularly in the 
functional variables. As with Building A, the occupants in Building B perceive a decline in the effective use of space and a loss of personal storage. Higher occupant numbers, specifically in the IT department where density has reached one person per $4.4 \mathrm{~m}^{2}$, is linked to a statistical decline in perceptions of overall comfort, health and productivity.

The decline in satisfaction with winter temperature in Building B (perceived mostly by the female occupants) cannot be associated with any one particular change in the building, and may be linked to operational set points. These may be due to tactical day-to-day FM decisions, and/or symptomatic of the low-energy design intention whereby internal conditions are allowed to swing with the seasons.

The occupancy levels in both buildings have increased beyond the original design allowances. Both buildings have demonstrated a capacity to cater for the increases, but this may be leading to occupant satisfaction penalties, particularly in occupants' perceptions of functional performance. Pockets of high density have shown the greatest decline in occupant satisfaction, suggesting that organisational performance may be at least partly dependent on density.

\subsection{Conclusions}

The longitudinal analyses have generated hitherto unavailable insights into trends in building performance that do not emerge from single surveys. The time-series approach, where context was monitored for a decade or more, has enabled an exploration of relationships between occupation comfort perceptions and physical and functional changes. The use of a structured set of building context definitions (categorised by physical, seasonal and functional characteristics) provided an opportunity to make structured associations between changes in physical factors and changes in occupant satisfaction. The use of outcome measures - perceived health, productivity and overall comfort - provided a headline indication of how the buildings have performed overall as they have aged and as their use had changed.

Although separation of the population samples by age and gender has been carried out, limitation on space precluded analysis in this paper. Suffice to say that the segregation of comfort scores by age did not generate additional insights. However, separation by gender tended to show that women gave lower scores for satisfaction with temperature. These findings will be reported in future papers, and for the entire case study dataset of six office buildings.

Statistical analysis has identified some comfort perceptions that have changed significantly over time, while consistent downward trends are evident in other comfort variables. While these movement were not statistically different at the classic $p<0.05$ level of statistical significance, it is thought that subtle movements in occupant perceptions may provide trustworthy early warning of diminishing returns in functional performance. The more trustworthy the data can be shown to be, the more that the building design community could 
gain a greater understanding of the redundancy levels contained within their design parameters. However, that benefit would come with a caveat: greater understanding would not justify pushing the limits on such parameters, as thresholds for discomfort may be highly context-specific.

Such caution applies to all human perception data. The context-rich, case-study approach has only enabled likely associations to be made between physical context and comfort outcomes rather than prove causal links. In this, the research findings support the views of Leaman and Bordass (15) who wrote: "the cat's cradle of causality and association differs from one building to the next, making it dangerous to be over-assertive about causation without careful appreciation of the contexts". The case study buildings reported here possess properties that have changed over time and appear to have influenced the comfort and satisfaction perceptions of their occupants. Occupants' survey scores in the longitudinal studies have also made it possible to indicate possible comfort risk factors. Some issues were particular to each building, while other factors were common to both.

The case studies had limitations. Longitudinal perceptions on density were not available as the BUS survey system never asked that question. Occupants' sensitivity to the numbers of people in their workplace and the relationships and effects of density on other comfort variables, such as noise, are therefore not known. Furthermore, while the BUS survey asks five questions about noise disturbance, there are no measured acoustic parameters against which occupant perceptions can be compared. The researcher believes that on-site noise tests such as reverberation tests or speech intelligibility tests may quantify contributions from the physical environment that can be compared with perceptions, but such tests are expensive and invasive. Research into this issue is ongoing.

The advent of Soft Landings (16), where project teams are required to focus more on operational outcomes, has meant the greater use of occupant surveys in order to inform client requirements and the design brief. Repeat occupant surveys during a three year Soft Landings aftercare period can also provide a means of checking whether the occupants of a soft-landed building perceive that the desired outcomes are being met. The approach piloted in this paper demonstrates how a time series approach can be used to measure ongoing performance byond Soft Landings in order to inform facilities management interventions and highlight risks inherent in stressing the carrying capacities of buildings. If aspects that occupants value are sacrificed for greater space utilisation (leading to loss of cellular offices, smaller workgroups, and fewer people in close proximity to windows and control devices), then a decline in satisfaction and functionality can be expected to occur. 


\section{Acknowledgments}

The author gratefully acknowledges the support of the organisations owning the buildings and the enthusiasm and willingness of the occupants to take part in the surveys. The wise counsel of Adrian Leaman, George Baird, Bill Bordass and Gary Raw cannot be overstated.

Occupant response data may be available on request to the author. Availability will be dependent on permission being granted by the building owners and staff employers, and on successful completion of the doctorate thesis.

\section{References}

1 Womble SE, Girman JR, Ronca EL, Axelrad R, Brightman HS, McCarthy, JF. Developing baseline information on buildings and indoor air quality (BASE 94): Part 1 - study design, building selection, and building descriptions. In Maroni M, (ed.) Healthy Buildings, 1995; Milano, 1305-1310. Quality Handbook, New York, McGraw-Hill, 4.1-4.36.

2 Mendell MJ, Naco GM., Wilcox TG, Sieber WK. Environmental risk factors and work-related lower respiratory symptoms in 80 office buildings: an exploratory analysis of NIOSH data. 2003; Am. J. Ind. Med., 43: 630-641.

3 Bluyssen M, Fernandes E, Groes L, Clausen G. European indoor air quality audit project in 56 office buildings. 1996; Indoor Air. 6: 221-238.

4 Building Use Studies methodology. Available from: http://www.busmethodology.org/history/ [Accessed January 2017]

5 Burge PS, Robertson AS, Hedge A. Comparison of self-administered questionnaire with physician diagnosis in the diagnosis of the sick building syndrome. 1991; Indoor Air. 1: 422-427. doi:10.1111/j.1600-0668.1991.00006.

6 Wilson S, Hedge A. The Office Environment Survey: a study of building sickness. A study sponsored by the Health Promotion Research Trust. Building Use Studies Ltd, 1987.

7 Leaman A, Bordass W. Assessing building performance in use 4: The PROBE occupant surveys and their implications. Building Research \& Information. 2001; 29(2), 129-43.

8 Raw G J, (ed). A Questionnaire for Studies of Sick Building Syndrome. A report to the Royal Society of Health Advisory Group on Sick Building Syndrome. BRE Report. London: 1995.

9 De Vaus, D. Surveys in Social Research. 5th ed. Routledge; 2004

$10 \mathrm{Kim}, \mathrm{JK}$, de Dear, R. Nonlinear relationships between individual IEQ factors and overall workspace satisfaction. Building and Environment 49. 2012; p.33-40.

11 Frontczak M, Wargocki P. Literature survey on how different factors influence human comfort in indoor Environments. Building and Environment. 2011; 46: 922-937. 
12 O'Brien W, Gunay HB. The contextual factors contributing to occupants' adaptive comfort behaviors in offices - A review and proposed modelling framework. Building and Environment. 2014; 77-87.

13 Mann $\mathrm{H}$, Whitney $\mathrm{D}$. On a test of whether one of two random variables is stochastically larger than the other. Annals of Mathematical Statistics. 1947; 18, 50-60.

14 British Council for Offices. BCO Specification for Offices. 2014. $6^{\text {th }}$ Edition.

15 Leaman A, Bordass W. Productivity in buildings: the killer variables, 20 years on. In D. Clements-Croome (ed). Creating the Productive Workplace. $2017 \mathrm{ed}$. Oxford: Taylor \& Francis.

16 Bordass W, Bunn R, Leaman A, Way M. The Soft Landings Framework. BSRIA BG54. 2014. 2nd ed.

\section{Figures}

Figure 1: Explanatory graphic for the BUS summary charts.

Figure 2: Building A study results for 1998 based on mean scores on the BUS 1-7 point scale. Note that occupants' self-assessed productivity is on a $-20 \%-+20 \%$ scale.

Figure 3: Building A study results for 2011. Performances on all summary variables, with the exception of temperature in winter, have declined compared with 1998.

Figure 4: Building A study results for 2015. Temperature in summer and perceptions of health and productivity are now below their scale midpoints.

Figure 5: Building B study results for 2006. Temperature in summer is the only variable below the scale midpoint. Self-assessed productivity is ranked on a $-20 \%-+20 \%$ scale.

Figure 6: Building B study results for 2015. Temperature in summer has improved, but temperature in winter is below midpoint, along with perceived heath and productivity (ranked in 2011 on a $-40 \%-+40 \%$ scale).

Figure 7: the ground floor open-plan office created in a former teaching area.

Figure 8: The second floor open-plan office created in a former dining area.

Figure 9: Building A occupant perception of work area, 2011. 
Figure 10: Building A occupant perception of work area, 2015.

Figure 11: Sample distributions for summer temperature for window and non-window seats in Building A, 2011 and 2015. The distribution of comfort data covers $5^{\text {th }}$ to $95^{\text {th }}$ percentiles with outliers. Mean values are shown as diamonds, and median values by notches in the plots.

Figure 12: Sample distributions for winter temperature for window and non-window seats in Building A, 2011 and 2015. The distribution of comfort data covers $5^{\text {th }}$ to $95^{\text {th }}$ percentiles with outliers. Mean values are shown as diamonds, and median values by notches in the plots.

Figure 13: Sample distributions for overall comfort for window and non-window seats in Building A, 2011 and 2015. The distribution of comfort data covers $5^{\text {th }}$ to $95^{\text {th }}$ percentiles with outliers. Mean values are shown as diamonds, and median values by notches in the plots.

Figure 14: Sample distributions for perceived productivity for window and non-window seats in Building A, 2011 and 2015. The distribution of comfort data covers $5^{\text {th }}$ to $95^{\text {th }}$ percentiles with outliers. Mean values are shown as diamonds, and median values by notches in the plots.

Figure 15: Building B occupant perceptions of workgroup size, 2006.

Figure 16: Building B occupant perceptions of workgroup size, 2015.

Figure 17: Occupant density perceptions in 2015, Building B overall.

Figure 18: Occupant density perceptions in 2015, Building B IT Department.

Figure 19: Movement in functionality and space use variables in Building B. Data shown 5th and 95 th percentiles with outliers. Diamonds indicate means. Line through variable shows the modal value (the score that occurs most frequently).

Figure 20: Movement in functionality and space use variables in Building B IT department. Data shown 5th and 95th percentiles with outliers. Diamonds indicate means. Line through variable shows the modal value (the score that occurs most frequently). 


\section{Tables}

Table 1: Details of the BUS surveys carried out on the pilot studies. Data prior to 2011 are best obtainable estimates.

Table 2: Building A primary level context, physical and occupancy characteristics.

Table 3: Building A overall main seasonal scores. All mean values over the 17-year period are universally in decline.

Table 4: Building A overall: Nest 4 outcome variables (Occupant perceptions).

Table 5: Building A control over environment factors.

Table 6: Seasonal variable scores for the open-plan office spaces compared with cellular and non-office spaces.

Table 7: statistical analysis of window and non-window comfort variables for Building A by window and non-window respondents.

Table 8: Mann-Whitney U-test scores for Building A (unpaired samples) for functional variables.

Table 9: Mann-Whitney U-test scores for Building A (unpaired samples) for functional variables by work group size, 2015.

Table 10: Outcome variables for Building A open-plan offices compared with cellular and non-office spaces.

Table 11: Building B primary level nest - physical and occupancy characteristics.

Table 12: Building B second level nest - reported characteristics. Key changes over time shown in red.

Table 13: Building B third level context, main seasonal contexts (BUS thermal and air quality perceptions).

Table 14: Perception changes for functional variables in Building B overall between 2006 and 2015.

Table 15: Building B: results of the outcome variables.

Table 16: Mann-Whitney U-test scores (unpaired samples) for Building B, IT department. 
Table 17: Building B IT department outcome variables (BUS perceptions). 